\title{
Empirical Investigation of Spark-Ignited Flame-Initiation Cycle-to-Cycle Variability in a Homogeneous-Charge Reciprocating Engine
}

\author{
Philipp Schiffmann ; David Reuss ${ }^{2}$; Volker Sick ${ }^{2}$ \\ ${ }^{1}$ IFP Energies Nouvelles, Rueil-Malmaison, France \\ ${ }^{2}$ Department of Mechanical Engineering, University of Michigan, Ann Arbor, USA
}

\section{Abstract}

This experimental study investigates the flame initiation-period variability in the sparkignited homogeneous-charge TCC-III engine. The engine was operated with lean, rich, and stoichiometric, propane and methane, with and without nitrogen dilution. These operating conditions were chosen to systematically change the unstretched laminar flame velocity and the Markstein number. Traditional pressure measures, apparent heat release analysis, particle image velocimetry (PIV), and $\mathrm{OH}^{*}$ flame imaging were used to generate over 400 metrics for 750 cycles at each of the 34 tests at 11 operating conditions. A multivariate statistical analysis was used to identify the parameters important to the variability of the crank angle at $10 \%$ fuel mass-fraction burned (CA10), but not could reveal physical mechanisms or cause and effect.

The analysis here revealed that the combustion-phasing cycle-to-cycle variations (CCV) is established by the time of the notional laminar-to-turbulent flame transition that occurs by CA01, measured here from the flame-image growth. Both the Markstein number and stretched laminar flame speed were found to be important. The velocity magnitude and direction were found to correlate with fast and slow CA10 as found in early literature. It was also revealed that the shear-strength, a property of the strain-rate tensor at the scales resolved here $(1 \mathrm{~mm})$, deserves further investigation as a possible effect on CA10.

\section{Keywords}

internal combustion engine, TCC-III, homogeneous flame ignition, cyclic variability, multivariate statistical analysis, flame imaging, PIV

\section{Corresponding Author:}

David L. Reuss, Dept. of Mechanical Engineering, University of Michigan, W. E. Lay Automotive Lab., 1231 Beal Ave., Ann Arbor, MI, 48109-2133, USA

Emil:dreuss@umich.edu 


\section{Introduction}

Current and near-term engine technology for automobiles continue to employ nominally homogeneous spark-ignited (SI) reciprocating internal combustion engines (ICEs). Cycle-to-cycle variability, CCV, of SI-ICE combustion at the lean and dilute limits cause undesirable engine out emissions, and inhibits more efficient operation. Improvements in the operation require the knowledge of the physical processes that control the CCV for predictive simulation leading to better designs. Many possible sources of CCV in homogeneous-charge ICEs have been known for decades, based on inferences from incylinder pressure analysis of systematic variations in engine operation. An earlier review by Ozdor ${ }^{1}$ provides a summary, and a comprehensive study by Ayala et al. ${ }^{2}$ added to the field. There is renewed interest in the ICE spark ignition fundamentals with current efforts to select candidates for future fuels ${ }^{3-5}$, that may improve dilute operation. The large range of the physical time scales, spatial scales, and operating conditions controlling ICE combustion result in multiple physical and chemical processes that control the combustion CCV at any given operating condition. Consequently, it is difficult to experimentally isolate the physical processes that control the CCV.

Crank-angle resolved in-cylinder flow and scalar measurements over thousands of cycles are now possible such that detailed physical properties of stochastically burning cycles can be captured ${ }^{6}$. In addition, multi-cycle engine simulation of up to hundreds of cycles is now possible, using Reynolds-averaged Navier-Stokes, RANS ${ }^{7}$ and large eddy simulation, LES ${ }^{8-15}$. Even direct numerical simulations, DNS ${ }^{16,17}$, while not feasible for such multi-cycle simulations yet, have added critical understanding about engine fundamentals. These advances in both high-speed laser-diagnostic measurements and multi-cycle engine simulation have fostered collaborative studies intended to improve the prediction of combustion CCV and, eventually, fully predictive computer aided ICE design ${ }^{9,18-20}$. The goal of the collaborations is to identify the physical and chemical processes that must be captured in simulations for effective predictions and implement those into CFD packages. The scope of this study was to reveal which quantifiable metrics are most significant for the prediction of the flame initiation CCV. The analysis cannot identify the physical process(es) that must be captured for empirical prediction and simulation. Rather, the results are intended to identify and justify the necessary deterministic analysis of the physical processes.

This experimental study in the third-generation transparent combustion chamber optical engine, TCC-III, addresses the causes of CCV during homogeneous spark-ignited fired operation and builds on the previous study of flow CCV for motored operation ${ }^{21}$. The purpose is to provide a multi-parameter data set with sufficient number of operating parameters and engine cycles that multivariate analysis can be used to investigate the interactions of the competing physics and chemistry contributing to combustion CCV. In addition, the complete data set is available for CFD and combustion-model development and validation ${ }^{22-25}$. 


\section{Background}

Engine $\mathrm{CCV}$ is traditionally characterized by both the work and combustion variability, leading to engine noise vibration and harshness, $\mathrm{NVH}$, and undesirable engine-out emissions, respectively. Experimental characterization of ICE work and combustion CCV is first quantified by variability of measured in-cylinder pressure parameters, including peak pressure, location of peak pressure, and the integrated-work per cycle (indicated mean-effective pressure, IMEP). The relationship between work and combustion is ambiguous, since the phasing of the heat-release rate, duration, and combustionefficiency, can vary independently of the cylinder volume. Thus, the pressure parameters do not have a unique or unambiguous relationship with the burning rates ${ }^{26}$. In this study, the apparent heat release rate, AHRR, is used as the metric to separate the burning rate and mass fraction burned, MFB (cumulative AHRR), from the pressure. AHR analysis of the pressure was chosen as a single metric that can be applied to both measured and simulated pressure ${ }^{27}$, and this metric obviates estimating blowby and heat loss ${ }^{28,29}$. The combustion varies from cycle to cycle due to both the engine-flow CCV and the trappedmass $\mathrm{CCV}$ (volume-average temperature, pressure, and composition $\mathrm{CCV}$ ), amongst other factors, which can be caused by both intercycle and intracycle thermodynamic and flow variability ${ }^{1}$. Combustion phasing is particularly important as it affects both the efficiency of the work extraction, the thermodynamic state, and flow evolution (as forced by the geometry) experienced during the flame propagation. Matekunas ${ }^{26}$ demonstrated that for a fixed spark timing, $\mathrm{CCV}$ of homogenous-combustion phasing is mostly determined during the flame initiation, the period between the requested beginning of the ignition-plasma discharge, SOIgn, and 1\% mass burn fraction, CA01. Conceptually, this is the period between SOIgn, and the development of a turbulent flame. Therefore, CCV of the flame-initiation period duration affects the phasing of the turbulent flame propagation through the remainder of the charge (CA > CA01). Thus, the CCV of the early kernel growth, EKG, during the flame initiation period is the focus of this study.

In this study, the initiation period is characterized as the period between SOIgn and CA10. During that time, it is thought that the flame propagation changes from laminar to turbulent behavior. The pressure based AHR analysis at these early times is prone to high uncertainty due to pressure-measurement noise and the large dynamic range requirements for the pressure transducer and recording system (here 40-2000 kPa). To overcome this limitation of the pressure measurements, optical measurements of the early flame-kernel area growth (2-D projection of the 3-D volume) have been used to identify the transition between slow and rapid flame growth. Beretta et al. ${ }^{30}$ observed the early-flame-growth period between the start of ignition and the transition to a turbulent flame. This slow-tofast burning-rate transition rate was also observed by Arpaci et al. ${ }^{31}$, as revealed in transition of the flame's projected-area growth, $\log \left(A_{F}\right)$ versus $\log (t)$, plots. This concept was introduced by Abraham et al. ${ }^{32}$ for modeling ignition in RANS simulations, which is termed as the transition from a laminar to a turbulent characteristic time scale. The concept that the early flame kernel is a simple laminar flame is arguable. However, based on the simple time-scale argument, it is reasonable to test if the processes that have been shown to affect laminar flame propagation can affect the initiation process. The question is then, "do state properties (pressure, temperature, stoichiometry, dilution), differential 
diffusion (Lewis number) and flame stretch (Markstein number), which are known to affect laminar flames, influence the flame initiation period in an ICE"?

As a guide to develop suitable engine experiments, Schiffmann et al. ${ }^{33}$ addressed this question in a constant-volume fan-stirred combustion vessel, at room temperature (323 $\mathrm{K})$, elevated pressures ( 6 bar), and turbulence velocity fluctuations $\left(u^{\prime}=0.5 \mathrm{~m} / \mathrm{s}\right)$, that had low intensity compared to the engine. In that study, fuel type, equivalence ratio, nitrogen dilution, pressure, and fan speed were varied to systematically change the parameters known to affect laminar flames, namely, laminar burning velocity, $\mathrm{S}_{\mathrm{lo}}$, Lewis number, Le, of the deficient species, the Markstein number, Ma, and the turbulence (as controlled by fan speed). Methane and propane were compared in order to change the Lewis number of the deficient species independent of the equivalence ratio. Lewis numbers substantially different from unity are known to result in the formation of cellular-flame instabilities ${ }^{34}$. The Markstein number describes the influence of stretch rate on a mixture's laminar flame speed. Mixtures with negative Markstein numbers tend to develop unstable flames as regions with positive stretch (tension) experience an increase in flame speed, while positive Ma tend to be stable as regions with positive stretch experience a decrease in flame speed smoothing the flame. The range of these parameters in the constant-volume tests were chosen to fall within the operating limits of the fired TCC-III engine tests described here, as determined by preliminary engine testing. Results of the constantvolume combustion tests demonstrated that indeed these parameters, which affect laminar flames, impacted the early kernel growth within the comparatively benign turbulence and carefully controlled conditions of the constant-volume combustion vessel. The test matrix for the constant-volume vessel was then also used for the engine tests to assess if these "laminar-flame" parameters have any influence in an ICE.

Unlike the experiments in the combustion vessel, reciprocating ICE operation does not permit the systematic variation to change each of the parameters in isolation of the others. However, the engine tests here were conducted at $1300 \mathrm{rpm}$ and intake manifold absolute pressure (MAP) of $40 \mathrm{kPa}$ and thus have the advantage of containing all the relevant physics at relevant time and spatial scales. To systematically vary the properties that affect the laminar-flame physics, the engine was fueled with methane and propane at unity equivalence ratio, $\phi=1$, and lean, rich, and nitrogen dilution limit. It is important to note, though, that the 'limit' here is defined as the condition where the coefficient of variation, $\mathrm{COV}$, of IMEP reaches $5 \%$. This condition was chosen as a value of practical relevance in engine operation. Since this study focuses on CCV of the flame initiation period, CA10 is an appropriate metric of merit to correlate the tested parameters. The SOIgn was the same for both the $\phi=1$ and limit conditions so that the thermodynamic and flow conditions were nominally the same. IMEP is included here as the traditional and practical metric of merit; of course, IMEP CCV is affected by thermodynamics and flow $\mathrm{CCV}$ after CA10 as well. Measurements presented here include dynamic pressures, spark-discharge energy and duration, high-speed particle image velocimetry, PIV, and $\mathrm{OH}^{*}$ imaging of the early flame growth. Metrics derived from the operation variables and measurements resulted in over 400 parameters for statistical correlation with IMEP and CA10. Residual gas levels were estimated using a GTPower analysis to be on the order of $10 \%$ but since no cycle-resolved residual-gas measurements were available, internal EGR was not considered as a parameter in this study. As a prescreening, single-parameter 
correlation was performed first to identify the most correlated parameters. Then, a multivariate analysis was performed to assess the interactions between the parameters upon the early kernel growth.

In the following pages, the engine experiments and measurements are described, with each section describing the analysis used to compute the parameters in the statistical analysis. Tables 1 and 2 summarize the operating conditions and the parameters included in the statistical analysis. The results section first summarizes the engine operation, then describes statistical-analysis methodology and results.

\section{Experiment measurements and metrics}

The third-generation transparent combustion chamber optical engine, TCC-III, is illustrated in Fig. 1, with specifics given in Table 1. This is a single-cylinder, sparkignited, two-valve, four-stroke-cycle, pancake-shaped-combustion-chamber engine with a transparent liner and piston. The geometric compression ratio is 10:1, and bore $\mathrm{x}$ stroke of $92 \times 86 \mathrm{~mm}$. A full quartz liner with a Bowditch piston and $70 \mathrm{~mm}$ piston window provided maximum optical axis. This research engine was designed at General Motors Research and Development as a canonical reciprocating ICE specifically to facilitate optical access and to provide a simple geometry to facilitate CFD-mesh generation. The combination of a pancake-shaped combustion chamber, large piston-to-valve diameter ratio $(92 \mathrm{~mm} / 30 \mathrm{~mm})$, and undirected ports produces large CCV of the large-scale, motored flow structures ${ }^{35,36}$.

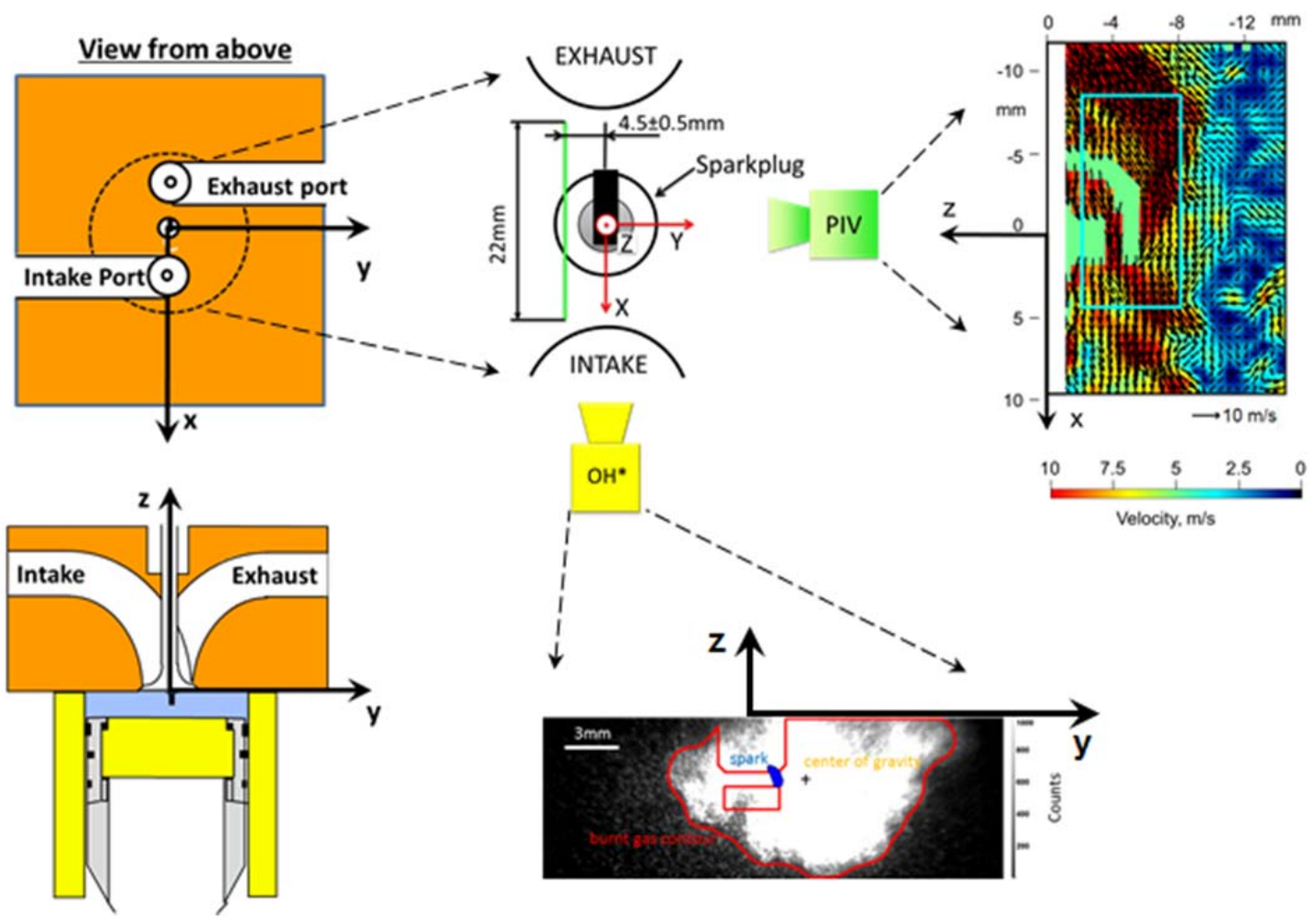

Figure 1. TCC-III engine geometry, fields-of-view for optical measurements and sample $\mathrm{OH}^{*}$ and PIV velocity flow field images. 


\begin{tabular}{|l|c|l|c|}
\hline Bore $(\mathrm{cm})$ & 9.20 & Exhaust-valve closing (ATDCE) & 12.8 \\
\hline Stroke $(\mathrm{cm})$ & 8.60 & Intake-valve closing (ATDCE) & 240.8 \\
\hline Clearance @ TDC $(\mathrm{cm})$ & 0.95 & Exhaust-valve opening (ATDCE) & 484.8 \\
\hline Comb. chamber vol. $(\mathrm{cc})$ & 63.15 & Intake-valve opening (ATDCE) & 712.8 \\
\hline Top-land crevice vol. $(\mathrm{cc})$ & 0.37 & Steady-flow swirl ratio & 0.4 \\
\hline Spark-plug crevice vol. $(\mathrm{cc})$ & 0.02 & Engine speed (rpm) & 1300 \\
\hline Swept volume (cc) & 571.7 & Intake MAP $(\mathrm{kPa})$ & 40 \\
\hline Geometric CR & 10.0 & Exhaust MAP $(\mathrm{kPa})$ & 101.5 \\
\hline Effective (IVC) CR & 8.0 & Fuel (plus toluene LIF tracer) & $\mathrm{CH}_{4}, \mathrm{C}_{3} \mathrm{H}_{8}$ \\
\hline Con.-rod length $(\mathrm{cm})$ & 23.5 & Equivalence ratio & $0.66-1.56$ \\
\hline Piston-pin offset $(\mathrm{cm})$ & 0.0 & SOIgn (ATDCE) & 342 \\
\hline
\end{tabular}

Table 1. TCC-III engine geometry, valve timing and operation.

For the fired operation presented here, the intake and exhaust systems are identical to the previous motored study ${ }^{21}$, which was designed in anticipation of these fired tests. The spark plug is on the engine cylinder axis, with a standard $2.4 \mathrm{~mm}$ diameter center electrode, and a standard ground strap oriented directly toward the exhaust valve. The glow-discharge ignition coil system [AEM] was operated at nominal $26.9 \mathrm{~mJ} \pm 3.6 \mathrm{~mJ}$ energy and $1.3 \mathrm{~ms} \pm 0.3 \mathrm{~ms}$ duration per discharge; the individual cycle plasma discharge energy and duration are logged in the archived data set. Complete details, a .stl file, and the Gamma Technologies GT Power ${ }^{\odot}$ model of the engine, intake, and exhaust systems are available at the University of Michigan archive ${ }^{25}$.

\section{Pressure measurements}

The absolute pressure measurements were recorded every 0.5 crank angle degree, CAD, with piezo-resistive transducers at five different locations: the intake and exhaust plenum-pipe interfaces, the intake and exhaust runner-port interfaces, and in the cylinder. Here, crank angles are reported in degrees after top-dead-center exhaust, ATDCE. The piezo-electric in-cylinder pressure transducer was pegged to the $10 \mathrm{CAD}$ average intake port pressure centered around 135 ATDCE, as suggested by the agreement between the measurements and the 1-D simulation at that crank angle. The pressure and AHR were measured and analyzed during the closed portion of the cycle using a commercial hardware/software package [DSP Phoenix/CAS]. The individual-cycle heat release analysis follows that of Heywood [xx], where the intake and exhaust polytropic coefficients are used before and after TDC as computed for each cycle between 260 - 325 and 400 - 450 ATDCE, respectively. Averages are computed over the individual-cycle AHRR results. Mass fraction burned, MFB, at each CAD is computed as the fraction of the cumulative AHR starting at start of ignition, SOIgn, using the peak cumulative AHR as the final value. Of course, the AHR analysis is only useful for comparison and does not yield an absolute heat release, since it computes the net heat release between the combustion heating minus heat and mass (blow-by) losses. Further, final MFB does not include combustion efficiency or heat release after the peak cumulative AHR occurs, which is also a function of cooling by volume expansion. In this study, the MFB 
calculation is only used to define the EKG as the period between SOIgn, and $10 \% \mathrm{MBF}$, CA10.

\section{Flame - Area Measurements}

Flame-area and spark-plasma measurements were recorded simultaneously with the PIV measurements during the EKG period. The 2-D projection of the 3-D flame

chemiluminescence was recorded by a high-speed CMOS camera [Phantom 7.3, Vision Research] and lens-coupled high-speed intensifier [IRO-HS, LaVision]. The signal was filtered by a combination of two optical filters, a UG11 and a 330-nm short-pass filter, creating a bandpass that centers on $307 \mathrm{~nm}$ with a 25 -nm wide $10 \%$ cut-off to isolate the 306.4-nm band from emissions of other major combustion products over $330 \mathrm{~nm}^{37}$. The images were recorded every $2 \mathrm{CAD}$ after SOIgn from a view perpendicular to the PIV plane and have a spatial resolution of $0.5 \mathrm{~mm}$ as quantified with a Siemens star test pattern. An algorithm was used to automatically identify and separate the unburned- and burned-gas regions. First, all acquired images were flat-field corrected and a spatial calibration was applied. Then a dynamic-threshold was determined by taking the average of the maximum values in each image column minus one standard deviation of the image intensities. The dynamic threshold is necessary to accommodate the spatial and temporal changes in chemiluminescence intensity and background. This process enables a high degree of automation, facilitating the processing of hundreds of thousands of images. A sample of results from this procedure is shown in Fig. 2. The flame area is highlighted by the red outlines. Note that beyond the intensity threshold used to determine where the flame starts, additionally, geometrical constraints, i.e. piston surface at the bottom, and cylinder head and spark plug at the top, inform the determination of the flame area, $A_{f}(t)$. It is noticed that blurring in the intensifier setup and scattering of $\mathrm{OH}^{*}$ light lead to signals outside of geometrically possible locations.

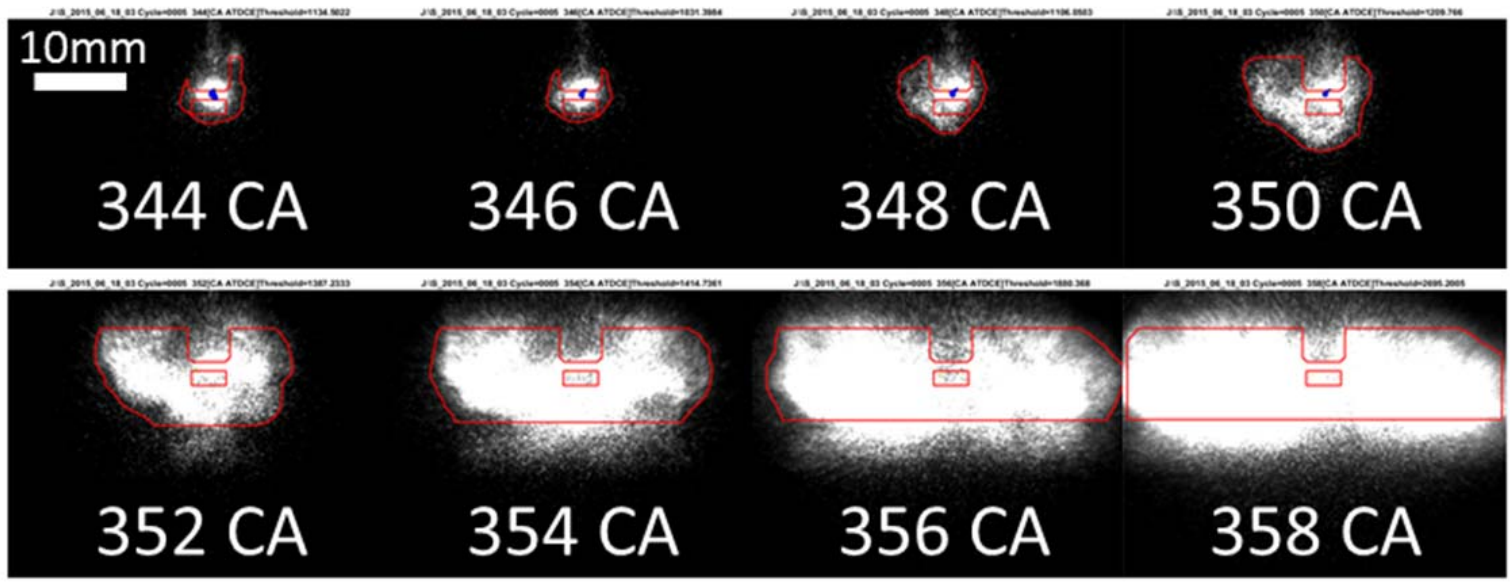

Figure 2 Example sequence of $\mathrm{OH}^{*}$ burned gas area growth of stoichiometric propane in a single cycle. 
The previously discussed laminar-to-turbulent flame transition, $\tau_{\text {lam-turb }}$, was determined from the $\log \left(\mathrm{A}_{\mathrm{f}}\right)$ vs. $\log (\mathrm{t})$ relationship as suggested by Arpaci et al. ${ }^{31}$ and is illustrated in Fig. 3. As a first estimate of the transition, the time of maximum positive curvature, $\dot{A}_{f}$, was determined. Then, a linear fit between $\log \left(\mathrm{A}_{\mathrm{f}}\right)$ and $\log (\mathrm{t})$ is created for the laminar and turbulent flame periods, respectively (cf. Fig. 3). The intersection of the lines is defined as laminar-to-turbulent flame transition. Note that the area roll-off in the late turbulent regime is due to the flame-imaging being truncated by the $11.5-10 \mathrm{~mm}$ high field-of-view, FOV, between 348 ATDCE and TDC; this truncation occurs prior to CA10 at $\phi=1$. This 2-D projection of the 3-D flame kernel is of course not an accurate measure of the mass burned. It is a pragmatic metric of the small early kernel to define $\tau_{\text {lam-turb }}$, which occurs well before CA01 (cf. Fig. 3). It is used as a quantifiable metric of the EKG prior to reliable pressure measurements.
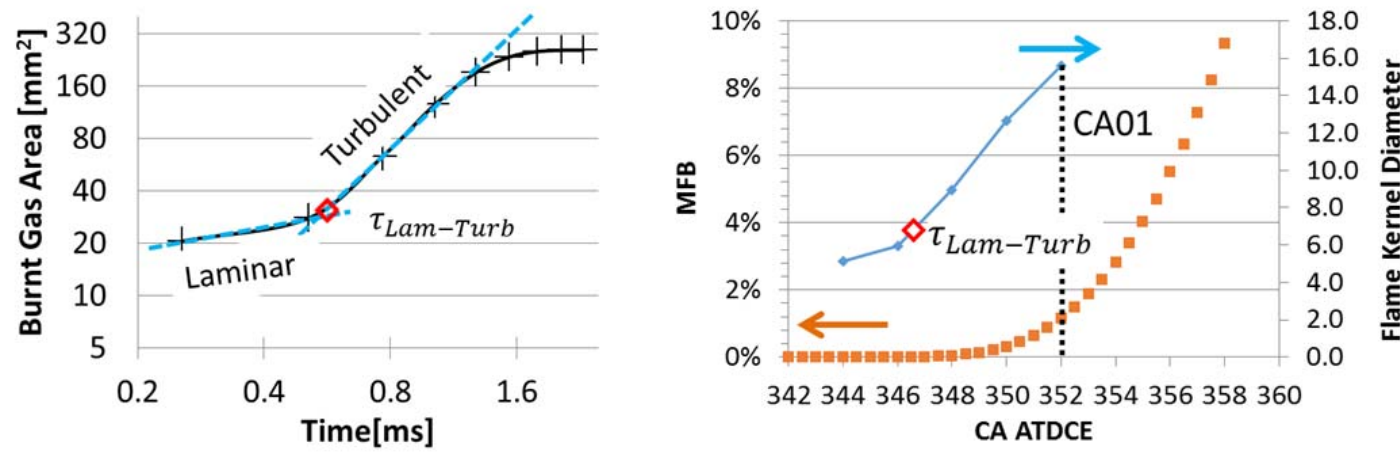

Figure 3 Determination of the transition time from laminar to turbulent flame propagation from $\mathrm{OH}^{*}$ images shown for stoichiometric propane combustion (left). The transition occurs when far less than $1 \%$ of fuel mass has been burned (right).

\section{Spark discharge measurements}

The ignition system used here was of the inductive-coil glow discharge type. The flow was not systematically changed. The delivered discharge energy and duration changed due to flow CCV alone. The spark-plasma energy and location were determined for each cycle. Discharge energy and duration for every cycle were computed from coil secondary voltage and current, recorded every $1 \mu$ s using a time-based acquisition system (National Instruments PCI 5105). A high-voltage probe (Tektronix 6015A) and current probe (Tektronix CP312) were used to measure the voltage and current delivered to the spark plug. The energy calculation was computed for the period between SOIgn and the time when the current reached zero and was corrected for the spark plug resistance. The average duration and electrical energy delivered to the gap of $1.6 \mathrm{~ms}(\approx 13 \mathrm{CAD})$ and $30 \mathrm{~mJ}$, respectively. The- intent was to provide robust, realistic, ignition at the limit conditions. No restrikes or misfires were observed at the dilute limits defined here. The spark discharge measurements were used to assure that there were no individual cycle discharge failures and for correlation with CA10 and IMEP. The spark-plasma location was computed, as a measure of the plasma stretch, from the same images used to 
determine the flame area. Since the plasma chemiluminescence is much larger than that of the nascent flames, it was isolated in the images by a second but higher threshold. Here the threshold was set to 16000 counts, which is close to the camera's saturation limit $\left(2^{14}\right.$ $=16383$ counts). The aperture and intensifier gain were set such that no saturation of the intensifier in the flame region was observed. An example of a spark-plasma and flame contour are shown in Fig. 4. Based on these plasma images, the area, plasma center-ofgravity position, and plasma eccentricity were computed for correlation with the CA10 and IMEP.

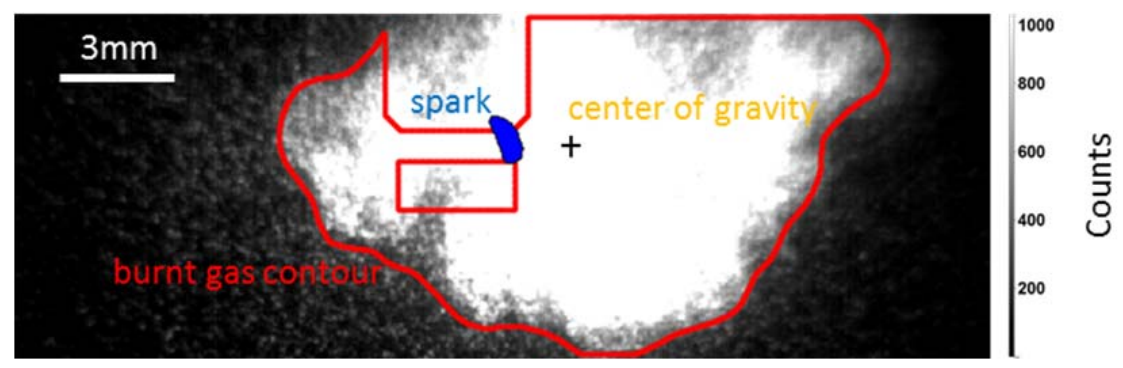

Figure 4 Example $\mathrm{OH}^{*}$ recognized contour of burned gas (red), burned-gas center of gravity (black cross) and spark plasma (blue), for stoichiometric propane combustion

\section{Velocity measurements}

High-speed PIV was used to measure the two in-plane velocity components of the flow in the unburned gas. The homogeneous intake fuel-air mixture was seeded with $1-\mu \mathrm{m}-$ diameter silicon-oil droplets (Dow Corning $510^{\circledR}$ fluid produced by a TSI Inc. 9603A atomizer). The particles were illuminated with dual high-speed 532-nm lasers at $1 \mathrm{~mJ}$ per pulse (Quantronix, Hawk II, Nd:YAG, TEM ${ }_{00}$ ), and images were recorded every CAD with a high-speed CMOS camera (Vision Research Phantom v7.3) from 320

to 360 ATDCE. Cross-correlation of images, using frame-straddling of the two laser pulses, resulted in one velocity field every two CAD. Details of the hardware and the PIV image analysis, using commercial software (LaVision DaVis 8.2), are available elsewhere ${ }^{38}$. The spatial resolution was $1 \mathrm{~mm}$ as determined by the 1 -mm-thick laser sheet and the $1 \times 1-\mathrm{mm}(32 \times 32$-pixel $)$ interrogation windows on a $0.5 \times 0.5-\mathrm{mm}$ grid $(50 \%$ interrogation-window overlap). The velocity dynamic range was 0.6 to $25 \mathrm{~m} / \mathrm{s}$, for the $10-\mu$ s laser-pulse separation and 0.2 - to 8-pixel-displacement criterion ${ }^{39,40}$. Velocity gradients were computed using central differencing on the grid interior, with one-sided differencing at the boundaries. The measurement plane was offset by $4.5 \mathrm{~mm}$ from the spark gap ( $y=-4.5 \mathrm{~mm}$, Fig. 1) to avoid scattering from the spark-plug elements.

For the statistical correlations with CA10 and IMEP, one-per-cycle velocity parameters were created by spatially averaging the $\mathrm{V}_{\mathrm{x}}$ and $\mathrm{V}_{\mathrm{z}}$ components, the velocity magnitude, $|\mathrm{V}|$, and the acceleration, $\Delta|\mathrm{V}| / \Delta \mathrm{t}$, in the $6 \times 12-\mathrm{mm}$ region $(x: \mathrm{z}=-2 \rightarrow-8 \mathrm{~mm}:-8 \rightarrow+4 \mathrm{~mm})$ near the sparkplug (cf. blue box in Fig. 1). In addition, three spatially averaged 2-D strain-tensor components, $E_{i j}=\partial V_{i} / x_{j}$, were computed and spatially averaged for each cycle. The von Mises strain, swirl strength, and shear strength were computed (Appendix A) and spatially averaged to yield one-per-cycle parameters. Though usually used in solid 
mechanics, von Mises strain has been applied to turbulent flows as an indicator of the maximum allowed shear ("yield") strain, at which an instability will attempt to reduce the strain ${ }^{41}$. Spatial averages were also determined for the negative Eigenvalue of the twocomponent strain tensor, called swirl strength, that was computed as an indicator of the presence of swirling structures in two-dimensional incompressible flows ${ }^{42}$. The positive Eigenvalue of the strain-tensor, called "shear strength" in the software package (LaVision Davis 8.2) was also computed. No study of flow topology was found in the literature that justifies this label or reveals what flow properties it characterizes. However, as it is the positive Eigenvalue it is interpreted here only as a flow property that is not swirl. It is recognized that application of these three strain-tensor metrics applied to this flow are not rigorous but were used in the spirit of exploration.

\section{Engine-test operating parameters}

The tests here were conducted at an engine speed of $1300 \mathrm{rpm}$. The intake total mass flow and exhaust back-pressure valve were adjusted to achieve $40 \mathrm{kPa}$ intake MAP, and $101.5 \mathrm{kPa}$ exhaust MAP. Ayala and Heywood state that they observed that $\mathrm{COV}_{\text {IMEP }}$ is proportional to the laminar flame speed divided by the eddy turn-over time ${ }^{2}$. Thus, fixed engine speed and ignition timing were used for the tests in the expectation that the eddy turn-over time at SOIgn is approximately the same for all the mixture conditions. The spark timing was fixed at 342 ATDCE, which is the maximum brake torque timing (MBT) for undiluted propane-air mixtures at $\phi=1$. This timing results in less than optimum late combustion for the dilute conditions, which would require earlier MBT timing. The dilute limits studied here were less than $8 \% \mathrm{COV}_{\text {IMEP. At }}$. the dilute limits the thermodynamic state (and possibly flow) at SOIgn was different for each cycle, since the trapped residual was altered by the combustion efficiency and EVO pressure from the previous cycle. The effect of the residual CCV was quantified here by the IMEP of the previous cycle for the statistical analysis.

To capture realistic CCV, the engine was continuously fired (rather than skip fired) but for only short durations $(\approx 100 \mathrm{~s})$ to prevent fouling of the piston window and cylinder by the silicone-oil seed. A rigorous systematic operating procedure was developed and followed to assure test-to-test repeatability and steady-state operation during the later cycles of each finite test sequence the pressure, spark discharge, and images were recorded.

The matrix of operating conditions and parameters is summarized in Table 2 . The nominal values shown are the average of the three or four tests conducted at each operating condition. The equivalence ratio $(\mathrm{A} / \mathrm{F})$, mass flows $(\dot{\mathrm{m}})$, and nitrogen dilution rates, are all based on the delivered flow rates. The engine was fueled with either methane or propane. Toluene was added as tracer molecule for PLIF temperature measurements that were carried out simultaneously but not reported in this study. The toluene mole fraction is included in the calculation of $\phi$, and contributes $10 \%$ to $15 \%$ of the fuel mass, depending on the level of air and nitrogen dilution. CHEMKIN PRO calculations of the adiabatic flame temperature and the thermal diffusivity of the mixtures used to determine laminar flame speeds showed that these did not change with or without toluene at the same equivalence ratios. Also, engine tests with propane at $\phi=0.69$ showed 
no differences in combustion behavior with or without toluene when the equivalence ratio was kept constant.

\begin{tabular}{|c|c|c|c|c|c|c|c|c|c|c|c|}
\hline & \multicolumn{4}{|c|}{ Methane } & \multicolumn{7}{|c|}{ Propane } \\
\hline & \multicolumn{4}{|c|}{ Air } & \multicolumn{3}{|c|}{ Air } & \multicolumn{3}{|c|}{$9 \% \mathrm{~N}_{2} \quad$ (by mass) } & \multirow{2}{*}{$\frac{19 \% \text { N2 }}{\text { Stoich }}$} \\
\hline & Leanest & Lean & Stoich & Rich & Lean & Stoich & Rich & Lean & Stoich & Rich & \\
\hline Equivaence Ratio & 0.66 & 0.69 & 1.00 & 1.21 & 0.67 & 1.00 & 1.56 & 0.79 & 1.00 & 1.43 & 1.00 \\
\hline m $\mathrm{O}_{2}[\mathrm{~g} / \mathrm{s}]$ & 0.48 & 0.48 & 0.47 & 0.47 & 0.48 & 0.47 & 0.46 & 0.44 & 0.43 & 0.42 & 0.38 \\
\hline$\dot{\mathrm{m}} \mathrm{N}_{2} \quad[\mathrm{~g} / \mathrm{s}]$ & 1.59 & 1.59 & 1.56 & 1.54 & 1.58 & 1.55 & 1.50 & 1.62 & 1.60 & 1.57 & 1.66 \\
\hline$\dot{m}$ Fuel $[\mathrm{g} / \mathrm{s}]$ & 0.070 & 0.075 & 0.109 & 0.132 & 0.078 & 0.119 & 0.185 & 0.084 & 0.108 & 0.154 & 0.096 \\
\hline$\dot{\mathrm{m}} \mathrm{C} 7 \mathrm{H} 8$ [g/s] & 0.012 & 0.012 & 0.012 & 0.012 & 0.012 & 0.012 & 0.012 & 0.012 & 0.012 & 0.012 & 0.012 \\
\hline$A / F$ & 25.3 & 24.0 & 16.8 & 14.0 & 23.0 & 15.5 & 10.0 & 19.6 & 15.5 & 10.8 & 15.5 \\
\hline $\mathrm{C}_{7} \mathrm{H}_{8}, \%$ fuel mass & 14.1 & 13.4 & 9.6 & 8.1 & 12.9 & 8.8 & 5.9 & 12.2 & 9.7 & 6.9 & 11.1 \\
\hline Le (difficient) & 1.0 & 1.0 & na & 1.14 & 1.75 & na & 0.97 & 1.86 & na & 0.99 & na \\
\hline $\mathrm{S} \mathrm{I}^{\circ}[\mathrm{m} / \mathrm{s}]$ & 0.55 & 0.61 & 0.96 & 0.86 & 0.74 & 1.22 & 0.57 & 0.77 & 0.98 & 0.59 & 0.68 \\
\hline$\delta L[\mathrm{~mm}]$ & 0.028 & 0.027 & 0.017 & 0.019 & 0.020 & 0.012 & 0.024 & 0.019 & 0.015 & 0.024 & 0.022 \\
\hline $\mathrm{Ma}$ & -0.8 & -0.5 & 2.7 & 4.8 & 6.2 & 3.4 & -1.4 & 5.2 & 3.4 & -0.3 & 3.4 \\
\hline$L \mathrm{MA}[\mathrm{mm}]$ & -0.015 & -0.013 & -0.045 & 0.09 & 0.125 & 0.040 & -0.033 & 0.101 & 0.050 & -0.007 & 0.074 \\
\hline IMEP [kPa] & 212 & 250 & 328 & 287 & 234 & 337 & 259 & 250 & 311 & 278 & 212 \\
\hline COVIMEP [\%] & 8.3 & 4.5 & 1.3 & 4.5 & 6.3 & 0.8 & 6.3 & 5.0 & 1.8 & 5.5 & 8.2 \\
\hline & 26_27 & 23_08 & 26_09 & 19_07 & 22_04 & 26_13 & 26_17 & 22_08 & 25_23 & 20_04 & 26_15 \\
\hline Data Set IDs & $26 \_25$ & 23_10 & 26_03 & 26_05 & 18_05 & $25 \_25$ & 25_21 & $26 \_21$ & 26_11 & 23_03 & 22_06 \\
\hline S_2015_06_nn_nn & 26_23 & 19_05 & 26_01 & 26_07 & 20_06 & 18_03 & 18_01 & 18_07 & 26_19 & 18_11 & 20_02 \\
\hline & & 19_03 & & & & & & & & & \\
\hline
\end{tabular}

Table 2 Matrix of test-operation conditions, estimated laminar parameters, and test identifiers in the archived data ${ }^{23-25}$.

The estimated laminar-flame parameters corresponding to the mixture composition at SOIgn are shown in Table 2 as well. The un-stretched laminar flame speed, $S_{l}^{0}$, flame thickness, $\delta$, and diffusivities were estimated at the measured polytropic pressure and volume-average temperature at SOIgn using a n-alkane mechanism ${ }^{43,44}$ in CHEMKIN PRO. The effective Lewis number, Le, was calculated using the procedure of Bechtold and Matalon ${ }^{45}$. The Markstein numbers were estimated from the relationships of Driscoll 46 .

$M a_{C_{3} H_{8}}=-8.6(\varphi-1.4)$, and $M a_{C_{4}}=3.3(\varphi-0.7)$.

The stretched laminar flame speed was estimated following the methodology of Law ${ }^{47}$ :

$$
s_{l}=s_{l}{ }^{0}-L \kappa
$$

where $\mathrm{L}$ designates the Markstein length, which was calculated from the fuel specific Markstein number correlation ${ }^{46} . \kappa$ is the global flame stretch rate due to the propagation of a spherical flame,

$$
\kappa=\frac{2}{r} * \frac{d r}{d t}
$$

At early times when the flame is small, the stretch rate is calculated from the ensemble average line-of-sight-integrated $\mathrm{OH}^{*}$ area for each condition. It is assumed that the flame is spherically shaped with a volume derived from the $2 \mathrm{D}$ images. Thus, the stretch rate here is intended to be a metric of stretch due to the expansion of the flame kernel, but does not capture the stretch due to the local flow gradients. The spherical shape 
assumption is less appropriate with increasing flame size as the flame is restricted by the piston and cylinder head, and that inaccuracy leads to an underestimation of the stretch rate at the higher-curvature flame fronts.

The integral scales in this engine were estimated from the measured velocity, taken over the full field of view ${ }^{21,38}$. At the time of ignition, the longitudinal scale in the $\mathrm{x}$ direction was estimated to be about $10 \mathrm{~mm}$, while the longitudinal length scale in the $\mathrm{z}$ direction and both transverse scales were found to be 3 to $4 \mathrm{~mm}$. Turbulent Reynolds numbers ranged from 50-500 and Kolmogorov scales were estimated to be between 50 and $150 \mu \mathrm{m}$, using highReynolds number scaling ${ }^{48}$. Depending on stoichiometry, the flame regime is thus estimated to range from the wrinkled flame into the thickened wrinkled flame regime. However, it is noted that the high Reynolds number scaling of the measured and estimated Taylor scale proved to be poor, off by a factor of 7 . Details of this analysis can be found elsewhere ${ }^{38}$.

\section{Results}

The results are divided into two sections. First, test-averaged engine combustion is quantified for the operating conditions in Table 2. Then, the parameters are statistically analyzed to assess which correlate with CA10 and IMEP CCV. The statistical prescreening and multivariate analysis procedures are described concurrently with the results, to help clarify the procedures.

\section{Average and COV of combustion at the operating conditions}

Comparisons of the test-average IMEP and $\mathrm{COV}_{\text {IMEP }}$ at the different operating conditions are provided in Table 2 , the limit operation defined to be $4 \%<\mathrm{COV}_{\text {IMEP }}<8 \%$. The choice of stoichiometric operation with MBT timing was intended to reveal CCV for the condition with the most robust laminar flame properties. That is the EKG flame would be so strong, so that only the most influential laminar flame parameters, with respect to $\mathrm{CCV}$, would be revealed. Operation at the dilute limits with the same SOIgn provides operation where the flame during EKG is slower, thicker, and with lower flame temperature, thereby revealing parameters with lesser influence that affect the lean limit. Comparing mass burn fractions for stoichiometric and lean-limit operation in Fig. 5 reveals that the IMEP is low not only because the delivered energy is low, but also because the combustion is quite late (CA50 > 380 ATDCE). Also, the burn duration is quite long, occurring well in to the expansion stroke $(\mathrm{EVO}=484)$. Thus, the late combustion from one cycle might affect the trapped-mass composition, thermodynamic, and flow of the next cycle. To test for this CA10 at each cycle, CA10(n), was correlated with the previous cycle $\operatorname{IMEP}(\mathrm{n}-1)$ and the exhaust port pressure from the previous cycle $\mathrm{P}_{\text {_Exh_Port }} \mathrm{P}(\mathrm{n}-1)$. 

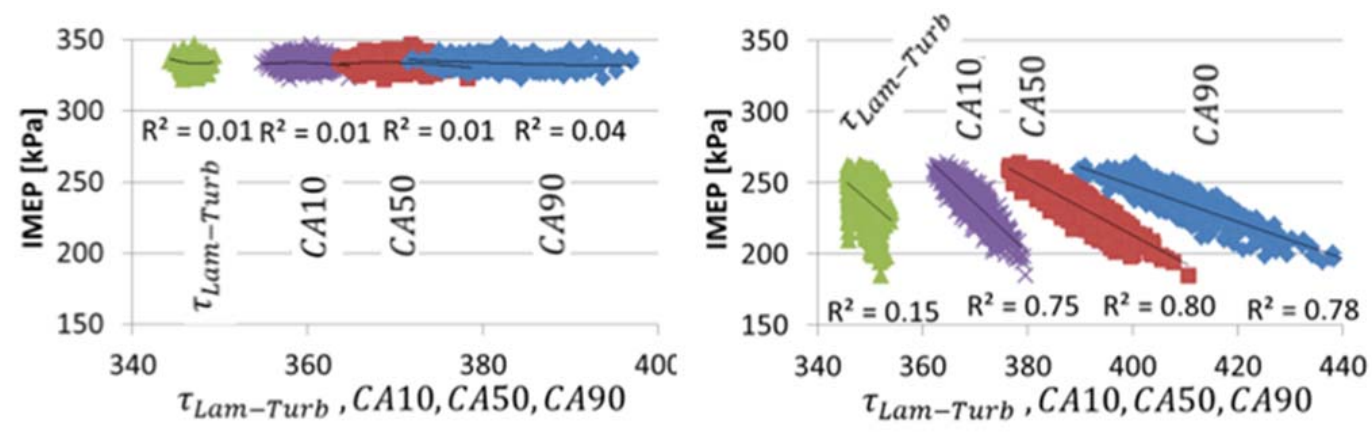

Figure 5. Combustion phasing, 10\%, 50\% and 90\% burn locations, from AHR from tests, at $\phi=1.0$ (left) and $\phi=0.67$ (right).

Figure 6 shows that the test average $\mathrm{COV}_{\text {IMEP }}$ is a strong nonlinear function of CA10, and that the tests here collapse on to a single curve. This demonstrates that the CCV IMEP is strongly dependent on the establishment of the CCV during the flame initiation period. Further, the dependence is valid for the range of Markstein numbers studied here, for both negative (unstable) and positive (stable) values of Ma.

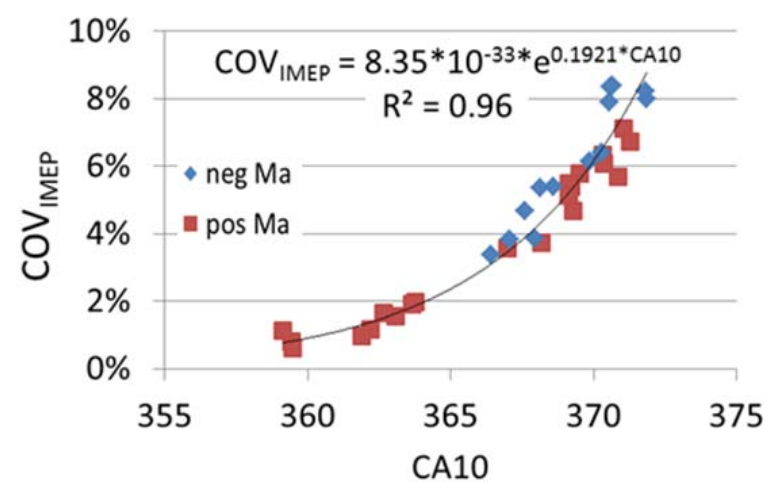

Figure $6 \mathrm{COV}_{\text {IMEP }}$ scales exponentially with CA10 for all tested conditions.

So far, CA10 was used as pressure-based metric of the EKG CCV.
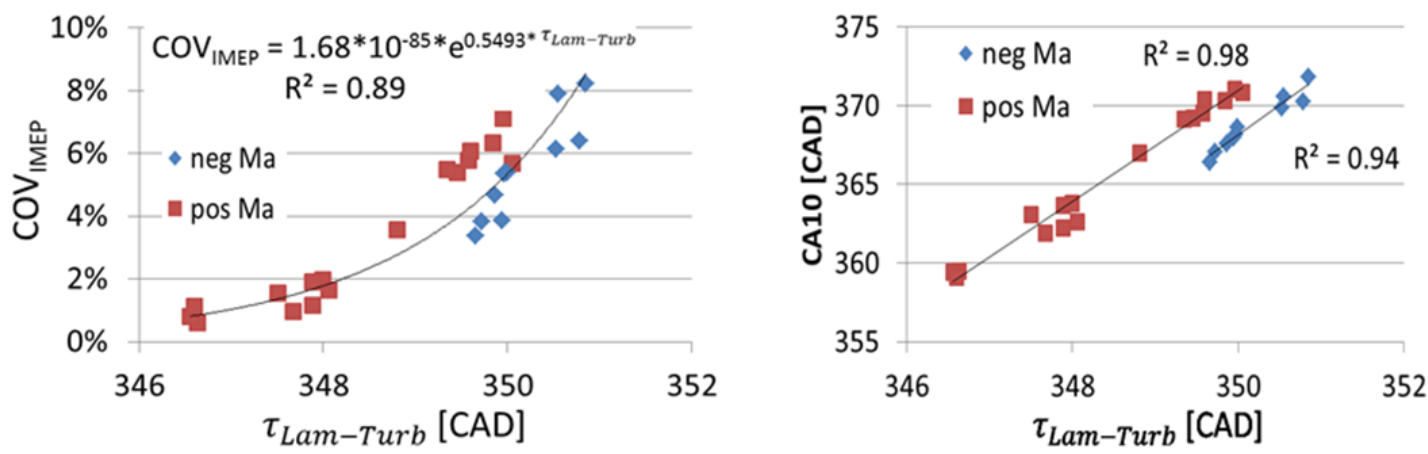
Figure 7 demonstrates that the flame area growth metric, $\tau_{L a m-T u r b}$, as an independent variable produces the same dependence of $\mathrm{COV}_{\text {IMEP }}$ observed in Fig. 6 for CA10 and shows a direct correlation between $\tau_{\text {Lam-Turb }}$ and CA10. Thus, the burning rate transition based on the projected-area growth, which occurs earlier than even CA01 (cf. Fig. 3), demonstrates that the CCV of combustion phasing occurs much sooner than can be detected by pressure measurements, and earlier than CA01. Although the test average $\tau_{\text {Lam-Turb }}$ correlates linearly with CA10 (cf. Fig. 7, right), the correlations between $\tau_{\text {Lam-Turb }}$ and CA10 within each of the 34 tests were weak $\left(\mathrm{R}^{2}<0.2\right)$. The role of $\tau_{\text {Lam-Turb }}$ is thus further assessed with the statistical analysis described below.
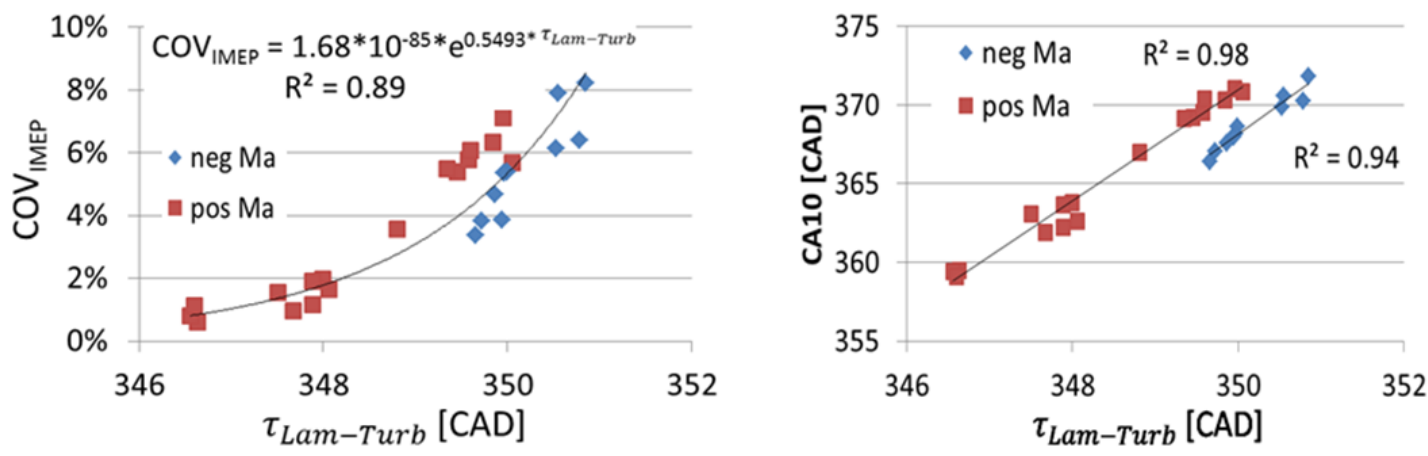

Figure 7. $\mathrm{COV}_{\text {IMEP }}$ is exponentially linked with the laminar-to-turbulent transition time (left). Thus, the test-averaged CA10 correlates linearly with laminar-to-turbulent time (right). Unstable negative Markstein mixtures advance faster to CA10 than positive stable flames.

As shown in Fig. 8 the transition time, $\tau_{\text {Lam-Turb }}$, shows a strong correlation $\left(\mathrm{R}^{2}=0.88\right)$ with the un-stretched laminar flame speed, $S_{l}^{0}$, while transition flame radius, $r_{\text {Lam-Turb }}$, is correlated somewhat less strongly. The transition time clearly decreases with increasing $S_{l}^{0}$. The test average radius of the flame kernel at $\tau_{\text {Lam-Turb }}$ shows a small increase with $S_{l}^{0}$, although the CCV of the flame radius is quite large compared to the average growth. The 3-4 mm average-radius range shown in Fig. 8 compares with the 11$10 \mathrm{~mm}$ range of the combustion-chamber height clearance for the 347-351 ATDCE crank angle range when the transition occurs (Fig. 7, right). It is likely that the large CCV of $r_{\text {Lam-Turb }}$ is due to asymmetric shapes (out of plane growth) of the flame kernels. Regardless, the results in Fig. 8 reaffirm this period is conceptually dominated by a laminar-flame physics. 

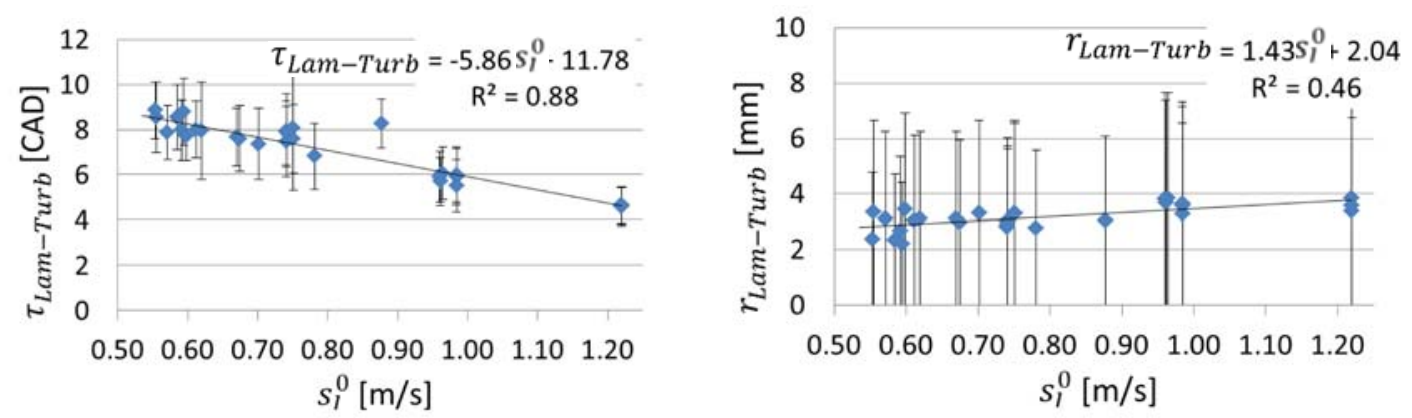

Figure 8. The laminar to turbulent transition time (left) and effective transition radius (right) as a function of laminar flame speed. Symbols indicate mean values for each test. Bars show \pm 1 standard deviation for the cycle to cycle variations, and become less than zero since the distribution is naturally skewed toward positive values.

The laminar-to-turbulent transition time and radius were also correlated with the stretched flame speed, $S_{l}$, but no higher correlations were found. However, Fig. 9 shows that correlations of $\mathrm{COV}_{\text {IMEP }}$ and CA10 with $S_{l}^{0}$ showed some improvement when correlated with $S_{l}$. This implies that there is some effect of flame stretch on the EKG, but perhaps after $\tau_{\text {Lam-Turb }}$.
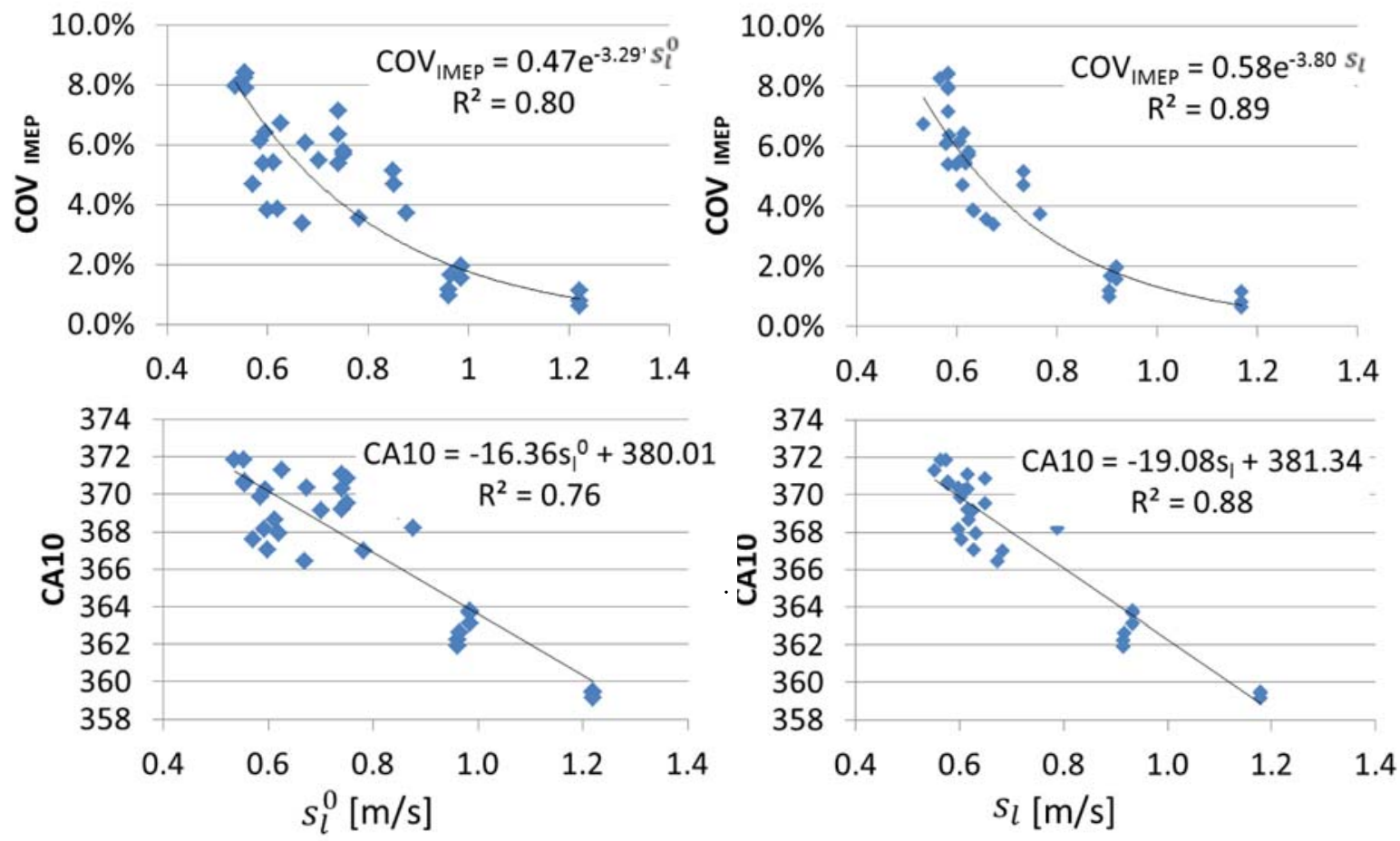

Figure 9. Correlations of combustion variability as measured by $\mathrm{COV}_{\mathrm{IMEP}}$ and combustion phasing with unstretched (left) and stretched (right) laminar flame speed. Including stretch effects leads to some improvement of the correlation. 


\section{Multivariate analysis of parameters correlated with CA10 and IMEP}

A multivariate model approach was used to determine which parameters of the 416 oneper-cycle and one-per-test parameters, listed in Appendix B, correlate best with CA10 and IMEP. To avoid overfitting the multivariate models, a reduced number of parameters was selected with a prescreening analysis. Then, a multivariate analysis of the most significant parameters was performed to tests for the significance of linear, square, and cross terms.

For the first step, parameter reduction, each of the 416 parameters was correlated with CA10, and correlated separately for IMEP. This was performed with the MATLAB fit $1 \mathrm{~m}^{\mathrm{TM}}$ algorithm, which includes a p-value analysis to quantify the statistical significance of each of the 416 variables on the CA10 combustion phasing. Here the p-value is set such that the lower $\mathrm{p}$, the more likely the parameter is correlated with CA 10 . Typically, a p-value of 0.05 is used as threshold of statistical significance, i.e. a 5\% likelihood that the two parameters are not correlated. Due to the large number of parameters in this study a threshold of $p=0.05 / 400$ was used, employing the Bonferroni correction. Figure 10 shows example results of the p-values graphically for six flow parameters, from all 34 test data sets, and 21 CAD from 320 ATDCE through TDC. It is important to note that Figure 10 is a matrix display, not a regular $x-y$ plot. The p-values of each of 416 parameters are shown rank ordered in columns for each of the 34 data sets. The p-values for six example parameters are highlighted in color, the remaining 410 values are assigned white bars for clarity. The horizontal band in each of the two panels indicates the range where $p \approx$ $0.05 / 400$. A clear clustering of the results for some parameters above that line emphasizes their significance in the correlations with CA10 whereas others below the line would be considered less significant and therefore were eliminated from further consideration. Among these examples in Fig. 10, the gradient parameters shear, swirl, von Mises strain, and velocity magnitude exhibit a statistical significance on CA10. The individual velocity component $\mathrm{V}_{\mathrm{z}}$ is never significant, whereas $\mathrm{V}_{\mathrm{x}}$ is or is not significant depending on the crank angle (vertical spread of $\mathrm{p}$ ). Other parameters that were identified as significant are not shown in this example but will be discussed further below. 

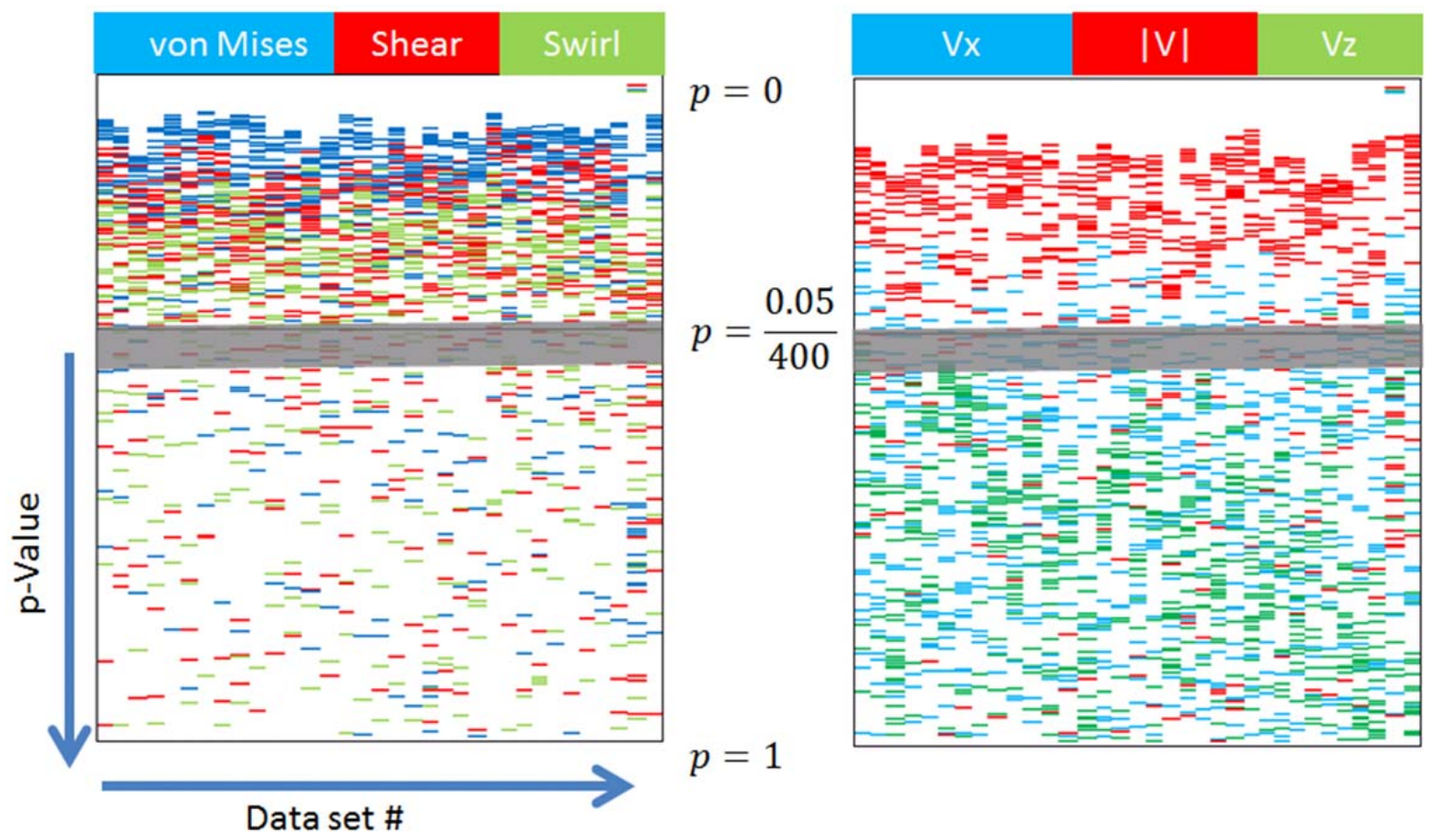

Figure $10 \mathrm{p}$-Value diagram to illustrate the statistical significance of each parameter on CA10. The colors indicate the parameter shown at the top each panel. The parameters above the threshold, indicated by the gray band, are considered significant because of their $p$-value is lower than $p \approx 0.05 / 400$. All 34 datasets are represented in the 34 columns of each panel. The multiple p-values shown at each dataset column are for measurements at 21 CAD from 320 ATDCE through TDC. Values for only six parameters are shown, others are suppressed from display as white bars.

The second step was a multivariate analysis of the most significant parameters used MATLAB ${ }^{\circledR}$ stepwiselm, that tests for a model with linear, square, and cross terms. Individual terms are added and removed after each iteration and checked for statistical significance. Only the linear coefficients were found to be important and retained for the final analysis. Thus,

$$
C A 10=B_{0}+\sum_{m=1}^{M} B_{m} x_{m},
$$

where $\mathrm{M}$ is the number of parameters in a particular test model. The number of variables identified as statistically significant was further reduced by successively testing models with reduced sets of parameters, to avoid overfitting the models. At each iteration only the most relevant and independent parameters were retained. For example, when Vx at $342 \mathrm{CAD}$ and $\mathrm{Vx}$ at 338CAD are identified as statistically significant, only the most relevant value is selected, because both are related as identified by the integral time scale of about 20CAD during this part of the cycle. This analysis identified the most significant parameters to be cycle number, spark duration, laminar-to-turbulent time, velocity 
magnitude at 342CA ATDCE, x-velocity component at 320 and 342CA ATDCE, and shear strength.

Figure 11 shows results of the model for $\phi=1$ with $9 \%$ nitrogen dilution (cf. Table 2) using the final seven parameters. Note that the indices for the parameters retained their original designation and thus are not consecutive.

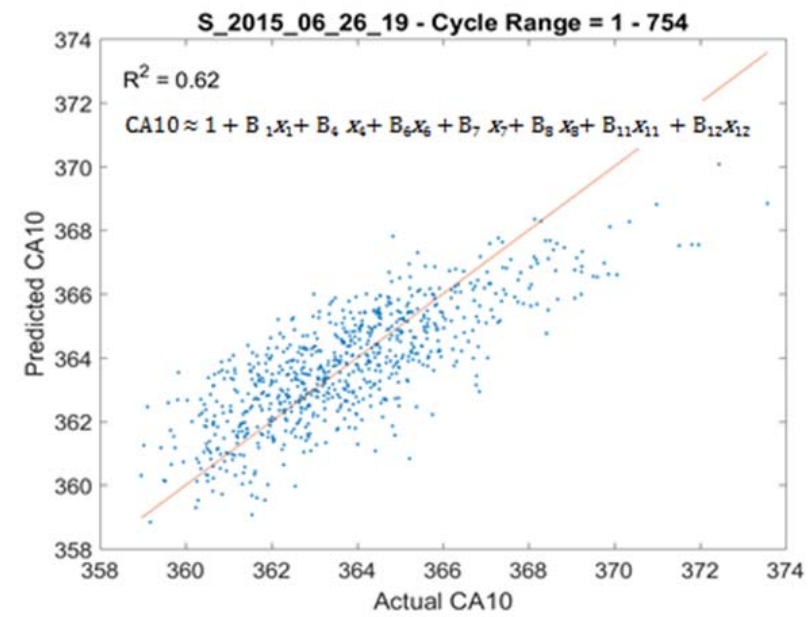

Figure 11. Example result of the model for CA10 using the seven final parameters for $\phi=1$ with $9 \%$ nitrogen dilution. The line shows Predicted CA10 = Actual CA10.

The $\mathrm{R}^{2}$ value for the overall model is a single parameter that quantifies the quality of the model correlation with CA10 and is shown for the 34 test datasets in Fig. 12. The model performance is adequately uniform across the test range, giving confidence that the model parameters have captured properties that control combustion phasing across a wide range of engine operating conditions. Although $R^{2}$ values between 0.3 and 0.6 may seem low, one needs to keep in mind that only data from a 2D cutting plane is available for several of the leading parameters but the flame is influenced by a three-dimensional flow. 


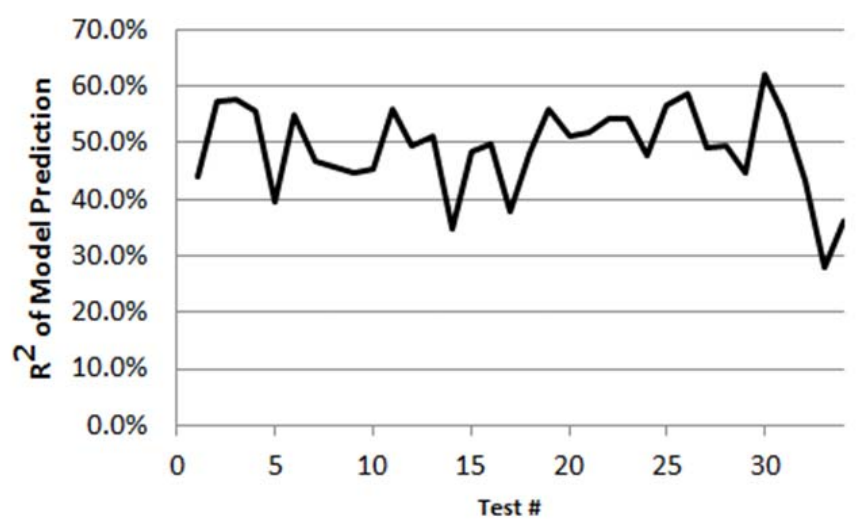

Figure $12 . \mathrm{R}^{2}$ of all seven -parameter model prediction for CA10 for all 34 engine operating conditions. Model quality remains at a substantially high level for all operating conditions, indicating that the seven-parameter linear model can capture cycle-to-cycle variability effects on combustion.

The multivariate model is not intended to be used in a predictive manner for an engine simulation. Its purpose is to identify leading correlations and point to critical parameters that need to be further investigated for physics-based models. However, the linear model coefficients have units and magnitudes connected to the input parameters, and thus are not directly comparable to allow identification of their relative importance. Therefore, the specific model equation is not presented and discussed here. Instead, the importance of each of the model parameters was quantified using the t-statistic value computed by MATLAB ${ }^{\circledR}$ stepwiselm. The t-Statistic is

$$
t=B_{m} /\left(\frac{\sigma_{m}\left(B_{m}\right)}{n-1}\right),
$$

where $\mathrm{B}_{\mathrm{m}}$ is the parameter coefficient in the linear model, and $\sigma_{\mathrm{m}}$ the standard deviation of the $\mathrm{m}^{\text {th }}$ coefficient of the linear model. As applied to the linear model from stepwiselm, the t-statistic tests the null hypothesis $\mathrm{H}: \mathrm{B}_{\mathrm{m}}=0$, that is, each coefficient of the linear model is not zero at the $0.05 / 400$ confidence level.

Figure 13 presents a summary of the t-Statistics for the multivariate model of the seven parameters, where the magnitude of the t value indicates the influence of each of the seven parameters on CA10 and IMEP. Here the sign of $t$ indicates if, with an increase of the parameter value, CA10 increases $(+)$ or decreases (-). For example, a higher shear strength value leads to a decreased CA10 and increased IMEP (better phasing for more work). Comparing the CA10 and IMEP t-values, the rank-order of the parameters is the same, but the magnitudes of the IMEP t-values are less. This makes sense from a deterministic point of view, since the integrated work is expected to be affected by other factors between CA10 and EVO, not captured by the parameters here. Also, the sign of the IMEP t-values is opposite to those of CA10, since most of the operating conditions were late as noted in the operating matrix (Figure 1). 
Focusing on the CA10 t-values, $\tau_{\text {Lam-Turb }}$ has the highest t-value and is positive. Thus, the longer the flame kernel needs to transition from laminar to turbulent the later CA10. At a minimum, this suggests that this optical-measurement is a redundant measure of CA10, and therefore valid and useful for investigating the flame initiation period prior to the availability of reliable pressure measurements. More important, it suggests that the physical and chemical process(es) that control CA10 CCV occur prior to $\tau_{\text {Lam-Turb. In }}$ this work, it is important to note that $\tau_{\text {Lam-Turb }}$ was identified to be directly correlated to the laminar flame speed, which in itself is a strong function of temperature.

The cycle \# has almost as high a magnitude as $\tau_{\text {Lam-Turb }}$, but is negative, revealing that CA10 decreases with increasing cycle number. This is consistent with the transient nature of each test as described earlier. During all tests, the engine is still in a thermal transient so that the engine is heating up with increasing cycle number. This increases the mixture temperature, and therefore the laminar flame speed, which would be expected to cause the CA10 phasing to advance in the progress of a test. The Teflon rings used in the optical engine are known to have improved blow-by performance as the piston and wall temperatures increase and higher spark plug temperatures might contribute as well. To reduce the impact of these effects only the last 400 cycles out of 754 for each test were used for the model building, yet the cycle-number effect still appeared to be important. The importance of each of these hypothesized parameters could be tested with the multivariate modeling approach used here, but would require measured parameters not available in this study, such as transient blow-by measurements and spark plug temperatures.

\section{CA10}

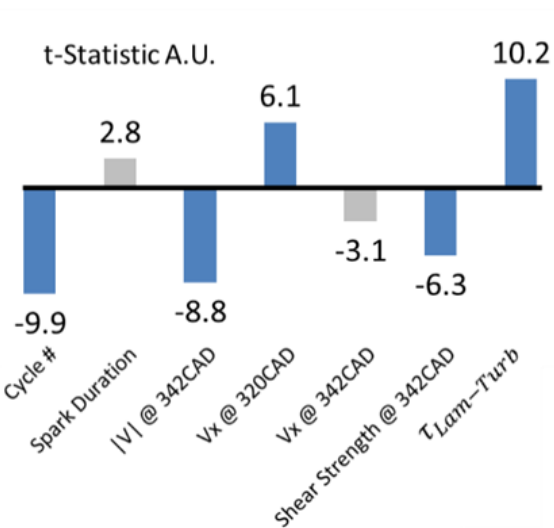

IMEP

t-Statistic A.U.
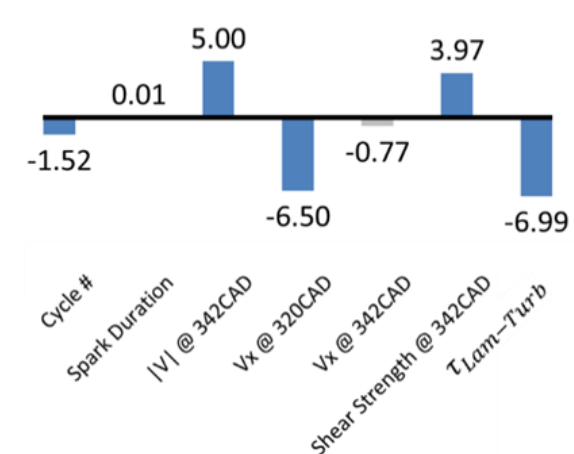

Figure 13 Importance of critical parameters to CA10 combustion phasing (left) and IMEP (right) for all test cases. The sign of each t-Statistic value indicates how that parameter affects CA10 and IMEP. Positive values lead to positive variation and vice versa.

Figure 13 also reveals that the spatially-averaged (cf. Fig. 1) flow velocities near the spark plug at SOIgn, |V|@342CAD and $\mathrm{V}_{\mathrm{x}} @ 342 \mathrm{CAD}$, are important, though the velocity direction seems to play a smaller role than the magnitude. This is consistent with previous observations that convection of the early flame kernel away from the sparkplug electrodes decreases the flame initiation period ${ }^{49}$. A positive value for $\mathrm{V}_{\mathrm{x}} @ 320$ implies 
that a flow directed away from the ground strap (cf. Fig. 1) at SOIgn is favorable for the early flame growth. The negative value for $\mathrm{V}_{\mathrm{x}} @ 342$ suggests flow towards the ground strap results in faster cycles. This result is counterintuitive based on heat transfer, but it may be the results of the measurement plane $4.5 \mathrm{~mm}$ from the spark plug being indicative of an unmeasured flow structure with a very different velocity within the gap.

The spatially-averaged shear strength has a negative t-value almost as large as that for $|\mathrm{V}|$. This implies that some feature of the resolved-scale 2-C 2-D strain tensor (here the positive Eigenvalue not associated with swirl) is significant in deceasing the CA10. This result suggests further study of the properties of the "shear strength" is warranted.

Compared to the flow, the spark duration has a smaller effect on CA10 phasing. Nonetheless, longer duration sparks are associated with later CA10. It is known that the plasma is affected by the flow; low flow velocities lead to longer discharges with less energy deposition, in turn leading to delayed combustion. Thus, from a deterministic view, CA10 may not be affected by the spark duration, but both may be responding to the flow.

\section{Analysis of late burning cycles}

The multivariate analysis created a model, sampling the 1/cycle parameters. However, $\mathrm{S}_{1}$ and $\mathrm{Ma}$ (as computed here) change with operating condition but not from cycle to cycle. To assess their effect on the initiation period, the two-sample t-test was applied. The procedure is illustrated with the following example. Here, the mean values of the seven parameters that were identified above were determined for the $10 \%$ slowest burning cycles in each test, as measured by CA10. The means were compared with the mean value of the full distribution of the same test. In this case the t-test is testing the null hypothesis that two mean values are equal $\mathrm{H}_{0}: \mu_{1}=\mu_{2}{ }^{50}$, where

$t=\frac{\overline{y_{1}}-\overline{y_{2}}}{s_{p} \sqrt{\frac{1}{n_{1}}-\frac{1}{n_{2}}}}$

with $\overline{y_{1}}-\overline{y_{2}}$ being the difference in the means of two mean output values, here actually CA $10, S_{p}$ an estimate of the common variance, and $\mathrm{n}$ the sample sizes. $S_{p}$ is computed as $S_{p}^{2}=\frac{\left(n_{1}-1\right) S_{1}^{2}+\left(n_{2}-1\right) S_{2}^{2}}{n_{1}+n_{2}-2}$

with $S_{1}^{2}$ and $S_{2}^{2}$ being the variances from the individual samples. The variance is the square of the unbiased standard deviation and is calculated according to

$S^{2}=\frac{\sum_{i=1}^{n}\left(y_{i}-\bar{y}\right)^{2}}{n-1}$

If the magnitude of the t-Statistic is less than 2 , there is only a weak influence of the parameter on the result. If the magnitude is over 5, the influence of the output parameter on the result is considered strong.

The t-statistics are used in Figure 14 to show the change in CA10 sensitivity to laminar flame speed and Markstein number for the 34 different operating conditions. Shear and velocity magnitude later in the cycle are have a stronger impact for high laminar flame speed flames while velocities earlier in the cycle have the opposite effect. For unstable 
(low) Markstein numbers, flames show a lower sensitivity to cycle number $|\mathrm{V}|$, shear, and laminar-turbulent kernel growth time than higher Markstein number flames.
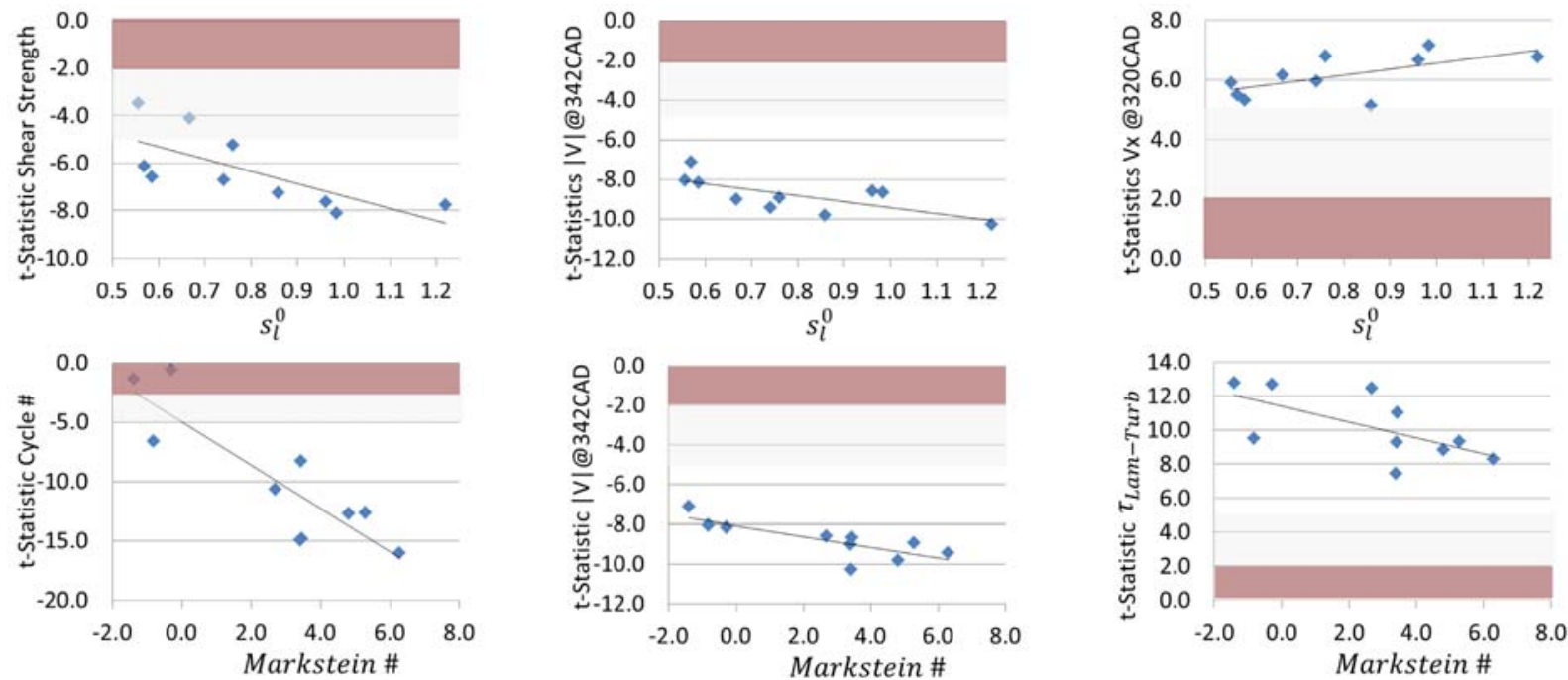

Figure 14 Change of importance of various parameters on cycle-to-cycle CA10 variations with different mixture properties. The ranges of weak and medium importance to model are colored in red and gray, respectively. Black lines indicate linear fits. Flame speeds are quoted in $\mathrm{m} / \mathrm{s}$.

The variability of the multivariate-model predictions at all operating conditions is similar according to $\mathrm{R}^{2}$ values in Figure 12, whereas the t-statistics show some change in importance in Figs. 13 and 14. Figure 15 illustrates how these trends can be understood and the t-Statistic values interpreted using shear strength at the time of ignition as an example. For the dilute $\phi=1$ condition, the distributions of all cycles and the $10 \%$ slowest cycles significantly overlap; the t-Statistic statistic of about -4 is significant but low. In comparison, at $\phi=1$ the all-cycle and slow-cycle distributions show significantly less overlap and have a t-statistic of about -8 . This indicates there is a weaker correlation between shear strength and CA10 for the dilute case, for which the slower flames should be more susceptible to perturbation and have more time between SOIgn and CA10 for flow-flame interaction. In contrast, the distributions of the undiluted case show cycles with larger values of shear strength are required to affect CA10, which is captured by the higher t-statistic. 

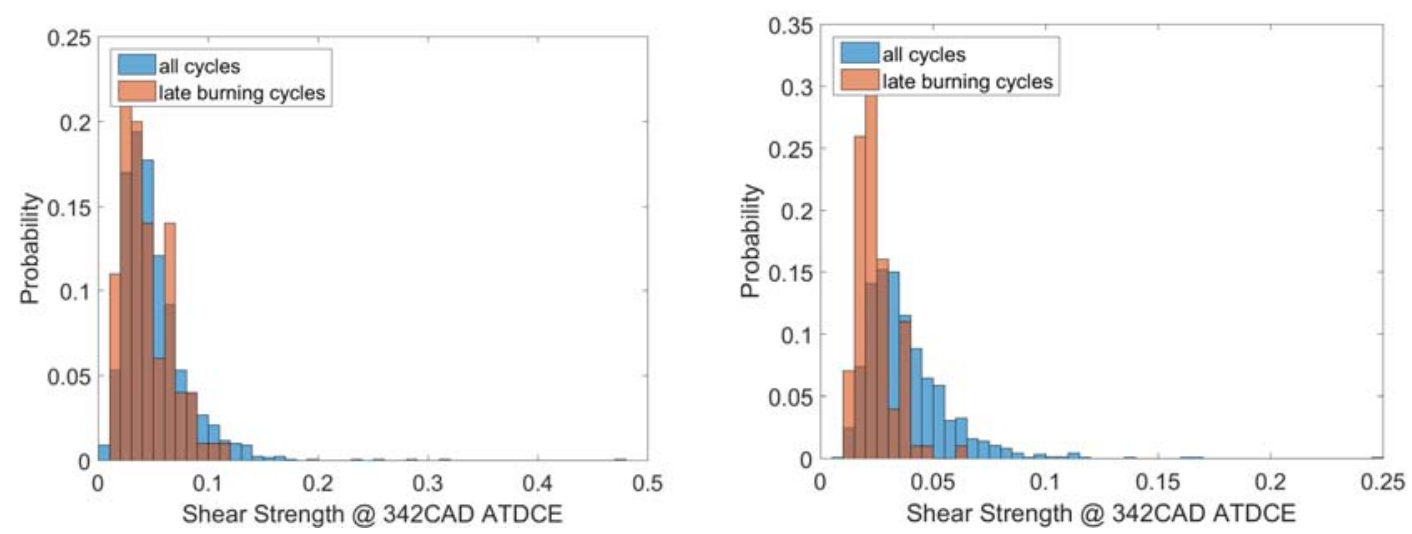

Figure 15 Probability distribution of $10 \%$ slowest burning cycles compared to all cycles for NITROGEN diluted stoichiometric propane (left) and undiluted stoichiometric propane air mixture (right). A t-Statistic value of about -4 for the distributions between late burn and all cycles quantifies that they are more similar for the dilute case (left) than for the undiluted mixture with a t-Statistic value of -8 (right).

\section{Summary and Conclusions}

A multi-diagnostic optical-engine experiment and statistical multivariate analysis were used to quantify the critical role of early flame development on cycle to cycle variability of the combustion phasing and power output of a homogeneous-charge spark-ignited four-stroke engine. A number of physical and chemical parameters and their relative importance to early flame variability were identified for a wide range of homogeneous spark-ignited engine operating conditions.

Fuel (methane or propane), equivalence ratio, and nitrogen dilution were systematically changed with fixed ignition timing, so that the thermodynamic state and statistical flow properties were held constant. Thermodynamic, fuel/air, and flow related parameters were statistically correlated with CA10 and IMEP to determine which had the highest effect. Strategically selected premixed methane and propane-air mixtures that cover both negative and positive Markstein numbers were used to quantify the effects of laminar flame speed, thermo-diffusive effects, and the role of the deficient species on the engine's variability behavior. External and in-cylinder pressures, various external temperatures, spark energies, flame contours, and velocity fields were measured simultaneously in an optical engine at $\mathrm{kHz}$ to $\mathrm{MHz}$ sampling rates to evaluate their respective contribution to the combustion event. Velocity fields, measured with high-speed particle-image velocimetry, were analyzed to provide flow metrics for the statistical correlation. Highspeed $\mathrm{OH}^{*}$ imaging was used to measure the projected flame area growth; this was used to quantify the notional transition of the early flame kernel from a laminar-to-turbulent time scale, $\tau_{\text {Lam-Turb }}$. 
The apparent-heat-release analysis demonstrated that the $\mathrm{COV}_{\mathrm{IMEP}}$ for each operating condition is correlated with combustion phasing, which is already established by CA10. Furthermore, the early and late cycles are shown to be established by $\tau_{\text {Lam-Turb }}$, which typically occurs before in-cylinder pressure diagnostics are sensitive enough to capture the growing flame $(<1 \% \mathrm{MFB})$. This suggests that $\mathrm{CCV}$ of the overall combustion phasing is determined in the earliest stages of the ignition event, which any ignition model must then capture for accurate prediction of combustion CCV. It was also revealed that CA10 is linearly correlated with $\tau_{\text {Lam-Turb }}$ for positive and negative Markstein number mixtures. With comparable slope, the correlation shows an offset such that unstable negative Markstein number mixtures show a higher growth rate from $\tau_{\text {Lam-Turb }}$ to CA10.

A multivariate statistical-model analysis of CA10 and IMEP with 416 parameters was performed first to identify the statistically most significant parameters using a p-value analysis. Then, multivariate modeling with a stepwise regression algorithm was used; neither nonlinear nor cross terms were significant. Multivariate linear models were sufficient to assess the predictive capabilities of the physical parameters. An all-linear model performed best to determine CA 10 and a t-statistics analysis performed to quantify the relative importance of the seven parameters. The leading factors in order of importance were identified as $\tau_{\text {Lam-Turb }}$, followed by velocity magnitude, $|\mathrm{V}|$, the headparallel velocity, $|\mathrm{Vx}|$, and shear strength, all most significant near the spark plug at the time of ignition.

The statistical analysis here has identified parameters that significantly affect the combustion initiation period. The analysis of course cannot identify the physical process(es) that must be captured for predictive simulation. Based on the parameters, operating conditions, and analysis here, the following conclusions can be stated. The combustion-phasing CCV is established by the time of the notional laminar-to-turbulent flame transition. This result supports previous suppositions that the laminar flame speed is a determining factor for the $\mathrm{COV}_{\mathrm{IMEP}}$ level. The accuracy in connecting laminar flame speed and $\mathrm{COV}_{\text {IMEP }}$ can be improved by about $10 \%$ when taking the modification of flame speed due to stretch effects into account. Especially for mixtures with Markstein numbers very different from one. This correction can be important even if the global flame stretch rate is only a rough estimate of local conditions. As such, taking mass diffusive properties into considerations may be significant to improve CFD modeling results especially for extremely lean and rich mixtures as found in stratified combustion modes. The importance of velocity magnitude and direction are consistent with previous studies in the literature. However, the importance of the shear strength is new and suggests that properties of the strain-rate tensor at the scales resolved here $(1 \mathrm{~mm})$ deserve further investigation.

\section{Acknowledgments}

This work was performed at the University of Michigan and funded by the GM-UM Automotive Collaborative Research Laboratory, Engine Systems Division. 


\section{Appendix A. Strain-tensor parameters for correlation with CA10.}

The von Mises strain, shear strength and swirl strength were computed from the 2-D tensor, $E_{i, j}=\Delta V_{i} / \Delta x_{j}$. These were calculated by the LaVision DaVis 8.3 software at each PIV-grid node. The von Mises strain is computed as

$$
E_{\text {von Mises }}=\frac{2}{3}\left[E_{x x}^{2}+E_{y y}^{2}-E_{x x} E_{y y}+3 E_{x y}^{2}\right]^{\frac{1}{2}}
$$

A single value for each cycle is obtained by averaging over the region indicated in Fig. 1.

The shear and swirl strengths are computed from the tensor Eigenvalues, for the 2-D tensor here of the form $a \pm \sqrt{b}$, where

$$
b=E_{x y} E_{y x}-\frac{1}{2} E_{x x} E_{y y}+\frac{1}{4}\left(E_{x x}^{2}+E_{y y}^{2}\right)
$$

The shear strength at each node is $\max (0,+b)$ and swirl strength $\max (0,-b)$. A single value for each cycle is obtained by averaging over the region indicated in Fig. 1. 


\section{Appendix B. Parameters correlated with CA10}

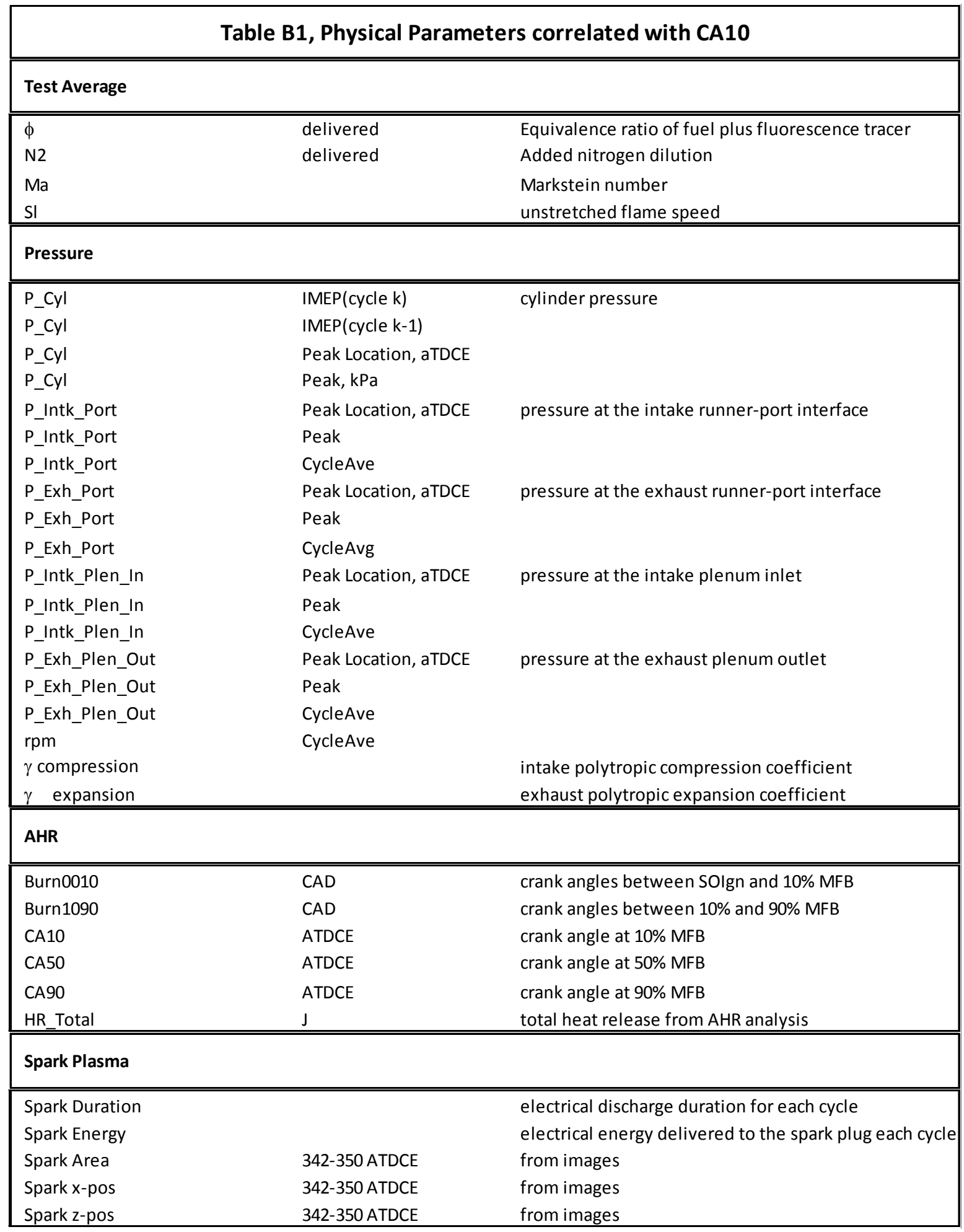




\begin{tabular}{|c|c|c|}
\hline \multicolumn{3}{|c|}{ Table B1 (cont.), Physical Parameters correlated with CA10 } \\
\hline Flame, Mie scattering & & \\
\hline $\begin{array}{l}\text { Ave Area } \\
\text { Ave Wrinkledness } \\
\text { Total Area } \\
\text { Total Wrinkledness } \\
\text { \# Burnt-Gas Pockets } \\
\text { dA/dCA }\end{array}$ & $\begin{array}{l}\text { 348-360 ATDCE } \\
\text { 348-360 ATDCE } \\
\text { 348-360 ATDCE } \\
\text { 348-360 ATDCE } \\
\text { 348-360 ATDCE } \\
\text { 349-359 ATDCE } \\
\end{array}$ & Burned gas area from images of 2-D laser sheet \\
\hline \multicolumn{3}{|l|}{ Flame, $\mathrm{OH}^{*}$} \\
\hline $\begin{array}{l}\mathrm{OH}^{*} \text { Area } \\
\text { Major/Minor axis length } \\
\mathrm{OH}^{*} \text { cg. x-pos } \\
\mathrm{OH}^{*} \text { cg. z-pos } \\
\text { Avg } \mathrm{OH}^{*} \text { Intensity } \\
\text { StdDev } \mathrm{OH}^{*} \text { Intensity } \\
\mathrm{OH}^{*} \mathrm{dA} / \mathrm{dCA} \\
\text { Area @ } \tau \text { lam-turb size } \\
\text { Lam log slope } \\
\text { Turb log slope } \\
\text { Inflection time [ms] } \\
\text { Lam log offset, [mm^2] } \\
\text { Turb log offset } \\
\tau \text { lam-turb [ms] } \\
\tau \text { lam-turb [CAD] } \\
\tau \text { lam-turb to CA10 [CAD] }\end{array}$ & $\begin{array}{l}\text { 344-360 ATDCE } \\
\text { 342-350 ATDCE } \\
\text { 344-360 ATDCE } \\
\text { 344-360 ATDCE } \\
\text { 344-360 ATDCE } \\
\text { 344-360 ATDCE } \\
345-359 \text { ATDCE } \\
\mathrm{mm}^{\wedge} 2 \\
\mathrm{~mm}^{\wedge} 2 / \mathrm{s} \\
\mathrm{mm}^{\wedge} 2 / \mathrm{s}\end{array}$ & $\begin{array}{l}\text { flame area at time of laminar to turbulent transition } \\
\text { Slope of } \log (A) v s \log (t) \text { during initial laminar growth } \\
\text { Slope of } \log (A) v s \log (t) \text { during turbulent growth } \\
\text { Location of maximum } d A / d t \\
\text { time from SOlgn to laminar-turbulent transition } \\
\text { CA from SOlgn to laminar-turbulent transition }\end{array}$ \\
\hline \multicolumn{3}{|l|}{ Velocity } \\
\hline $\begin{array}{l}|V| \\
V z \\
V x \\
\text { vonMises strain } \\
\text { Shear Strength } \\
\text { SwirlStrength }\end{array}$ & $\begin{array}{l}\text { 320-360 ATDCE } \\
320-360 \text { ATDCE } \\
320-360 \text { ATDCE } \\
320-360 \text { ATDCE } \\
\text { 320-360 ATDCE } \\
320-360 \text { ATDCE }\end{array}$ & $\begin{array}{l}\text { velocity magnitude averaged over sub area of Fig.1 } \\
\text { z-vel. component, averaged over sub area of Fig.1 } \\
\text { x-vel. Component, averaged over sub area of Fig.1 } \\
\text { (Appendix 1) averaged over sub area of Fig.1 } \\
\text { (Appendix 1) averaged over sub area of Fig.1 } \\
\text { (Appendix 1) averaged over sub area of Fig.1 }\end{array}$ \\
\hline
\end{tabular}

In addition, 133 coefficients from proper-orthogonal decomposition and independent component analysis of flow fields were included in the original analysis, but not presented here. 


\section{References}

1. Ozdor N, Dulger $M$ and Sher E. Cyclic variability in spark ignition engines: a literature survey. SAE Paper 940987. 1994.

2. Ayala FA and Heywood JB. Lean SI Engines: The role of combustion variability in defining lean limits. SAE 2007-24-0030. 2007.

3. Szybist J and Splitter D. Effects of Fuel Composition on EGR Dilution Tolerance in Spark Ignited Engines. SAE Int J Engines. 2016; 9: 819-31.

4. Jatana GS and Kaul BC. Determination of SI Combustion Sensitivity to Fuel Perturbations as a Cyclic Control Input for Highly Dilute Operation. SAE Int J Engines. 2017; 10.

5. Kolodziej C, Pamminger M, Sevik J, Wallner T, Wagnon S and Pitz W. Effects of Fuel Laminar Flame Speed Compared to Engine Tumble Ratio, Ignition Energy, and Injection Strategy on Lean and EGR Dilute Spark Ignition Combustion. SAE Int J Fuels Lubr. 2017; 10: 82-94.

6. $\quad$ Sick V. High Speed Imaging in Fundamental and Applied Combustion Research. Proceedings of the Combustion Institute. 2013; 34: 3509 - 30.

7. Scarcelli R, Richards K, Pomraning E, Senecal PK, Wallner T and Sevik J. Cycle-to-Cycle Variations in Multi-Cycle Engine RANS Simulations. SAE Paper 2016-01-0593. 2016.

8. Truffin K, Angelberger C, Richard S and Pera C. Using large-eddy simulation and multivariate analysis to understand the sources of combustion cyclic variability in a sparkignition engine. Combustion and Flame. 2015; 162: 4371-90.

9. Pera C, Richard S and Angelberger C. Exploitation of Multi-Cycle Engine LES to Introduce Physical Perturbations in 1-D Engine Models for Reproducing CCV. SAE 2001-0100127. 2012.

10. Rutland CJ. Large-eddy simulations for internal combustion engines -a review. International Journal of Engine Research. 2011; 12: 421-51.

11. Haworth DC. Large-eddy simulation of in-cylinder flows. Oil \& Gas Science and Technology. 1999; 54: 175-85.

12. Goryntsev D, Sadiki A, Klein M and Janicka J. Large eddy simulation based analysis of the effects of cycle-to-cycle variations on air-fuel mixing in realistic DISI IC-engines. Proc Comb Inst. 2009; 32.

13. Kuo T-W, Yang X, Gopalakrishnan V and Chen Z. Large Eddy Simulation (LES) for IC Engine Flows. Oil \& Gas Science and Technology. 2014; 69: 61 - 81.

14. Schmitt M, Hu R, Wright YM, Soltic P and Boulouchos K. Multiple cycle LES simulations of a direct injection natural gas engine. Flow Turbulence and Combustion. 2015; 95: 645 - 68.

15. Fontanesi S, Paltrinieri S, Tiberi A and D'Adamo A. LES Multi-cycle Analysis of a High Oerformance GDI Engine. SAE 2013-01-1080. 2013.

16. Pera $C$, Knop $V$ and Reveillon J. Influence of flow and ignition fluctuations on cycle-to-cycle variations in early flame kernel growth. Proceedings of the Combustion Institute. 2015; 35.

17. Schmitt M, Frouzakis CE, Tomboulides AG, Wright YM and Boulouchos K. Direct numerical simulation of multiple cycles in a valve/piston assembly. Physics of Fluids. 2014; 26: 035105.

18. Sick V, Reuss D, Rutland C, et al. A Common Engine Platform for Engine LES Development and Validation. In: Angelberger C, (ed.). LES4ICE. Rueil-Malmaison, France: IFP Energies Nouvelles, 2010. 
19. Baumann M, di Mare F and Janicka J. On the Validation of Large Eddy Simulation Applied to Internal Combustion Engine Flows Part II: Numerical Analysis. Flow, Turbulence and Combustion. 2013; 92: 299-317.

20. Baum E, Peterson B, Böhm B and Dreizler A. On The Validation of LES Applied to Internal Combustion Engine Flows: Part 1: Comprehensive Experimental Database. Flow, Turbulence and Combustion. 2013; 92: 269-97.

21. Schiffmann P, Gupta S, Reuss D, Sick V, Yang X and Kuo T-W. TCCIII - Engine Benchmark for Large Eddy Simulation of IC Engine Flows. Oil \& Gas Science and Technology. 2016; 71: 127.

22. Schiffmann P, Reuss DL and Sick V. TCC-IIII Data Repository. Ann Arbor, MI, USA: University of Michigan, 2017.

23. Schiffmann P, Reuss DL and Sick V. TCCIII Motored Full View. University of Michigan. 2017; https://doi.org/10.7302/Z2MS3QP.

24. Schiffmann P, Reuss DL and Sick V. TCCIII Fired Full View. University of Michigan. 2017; https://doi.org/10.7302/Z2H41PCD.

25. Schiffmann P, Reuss DL and Sick V. TCCIII Fired Spark Plug Region. University of Michigan. 2017; https://doi.org/10.7302/Z2CC0XNP.

26. Matekunas FA. Modes and Measures of Cyclic Combustion Variability. SAE 830337. 1983.

27. Shekhawat Y, Haworth DC, d'Adamo A, et al. An Experimental and Simulation Study of Early Flame Development in a Homogeneous-Charge Spark-Ignition Engine. In: Angelberger C, (ed.). Large-Eddy Simulation for Internal Combustion Engines. RueilMalmaison, France: IFP Energies Nouvelles, 2016.

28. Tian T, Wong VW and Heywood JB. A Piston Ring-Pack Film Thickness and Friction Model for Multigrade Oils and Rough Surfaces. SAE Paper 962032. 1996.

29. Heywood JB. Internal combustion engine fundamentals. McGraw-Hill, 1988.

30. Beretta GP, Rashidi M and Keck JC. Turbulent Flame Propagation and Combustion in Spark Ignition Engines. Combustion and Flame. 1983; 52: 217-45.

31. Arpacı VS, Ko Y, Lim MT and Lee HS. Spark kernel development in constant volume combustion. Combustion and Flame. 2003; 135: 315-22.

32. Abraham J, Bracco FV and Reitz RD. Comparisons of computed and measured premixed charge engine combustion. Combustion and Flame. 1985; 60: 309-22.

33. Schiffmann P, Sick V and Foucher F. Multi-diagnostics Analysis of Flow Induced Combustion Variability at SI Engine-Like Conditions. 18th International Symposium on the Application of Laser and Imaging Techniques to Fluid Mechanics. Lisbon, Portugal2016, p. 776 - 91.

34. Palm-Leis A and Strehlow RA. On the propagation of turbulent flames. Combustion and Flame. 1969; 13: 111-29.

35. Reuss DL. Cyclic Variability of Large-Scale Turbulent Structures in Directed and Undirected IC Engine Flows. SAE Paper 2000-01-0246. 2000.

36. Abraham PS, Yang X, Gupta S, Kuo TW, Reuss DL and Sick V. Flow-pattern switching in a motored spark ignition engine. International Journal of Engine Research. 2015; 16: 323-39.

37. Zhao $\mathrm{H}$ and Ladommatos N. Engine Combustion Instrumentation and Diagnostics. Warrendale, PA: Society of Automotive Engineers, 2001.

38. Schiffmann P. Root Causes of Cyclic Variability of Early Flame Kernels in Spark Ignited Engines. Mechnical Engineering. Ann Arbor: Michigan, 2016.

39. Westerweel J. Fundamentals of digital particle image velocimetry. Meas Sci Technol. 1997; 8: 1379-92. 
40. Megerle M, Sick V and Reuss DL. Measurement of Digital PIV Precision using Electrooptically-Created Particle-Image Displacements. Measurement Science and Technology. 2002; 13: 997 - 1005.

41. Ananiev S. On analogy between transition to turbulence in fluids and plasticity in solids. In: Hanjalić K, Nagano Y and Jakirlic S, (eds.). Turbulence, Heat and Mass Transfer 5. Dubrovnik, Croatia: Begell House, 2006.

42. Chong MS, Perry AE and Cantwell BJ. A general classification of three-dimensional flow fields. Physics of Fluids. 1990; 2: 765 - 77.

43. Sarathy S, Yeung C, Westbrook C, Pitz W, Mehl M and Thomson M. An experimental and kinetic modeling study of $\mathrm{n}$-octane and 2-methylheptane in an opposed-flow diffusion flame. Combustion and Flame. 2011; 158: 1277-87.

44. Sarathy SM, Westbrook CK, Mehl M, et al. Comprehensive chemical kinetic modeling of the oxidation of 2-methylalkanes from C 7 to C 20. Combustion and flame. 2011; 158: 2338-57.

45. Bechtold JK and Matalon M. The dependence of the Markstein length on stoichiometry. Combustion and Flame. 2001; 127: 1906-13.

46. Driscoll JF. Turbulent premixed combustion: Flamelet structure and its effect on turbulent burning velocities. Progress in Energy and Combustion Science. 2008; 34: 91-134.

47. Law CK. Combustion physics. Cambridge University Press, 2006.

48. Hinze JO. Turbulence, McGraw Hill, 1975.

49. Pischinger $\mathrm{S}$ and Heywood JB. How Heat Losses to the Spark Plug Electrodes Affect Flame Kernel Development in an SI-Engine. SAE 900021. 1990.

50. Montgomery DC. Design and analysis of experiments. John Wiley \& Sons, 2008. 